\title{
Do millennials value travel time differently because of productive multitasking? A revealed-preference study of Northern California commuters
}

\author{
Aliaksandr Malokin ${ }^{1} \cdot$ Giovanni Circella $^{1} \cdot$ Patricia L. Mokhtarian ${ }^{1}$ (D)
}

Published online: 12 February 2021

(c) The Author(s) 2021

\begin{abstract}
Millennials, the demographic cohort born in the last two decades of the twentieth century, are reported to adopt information and communication technologies (ICTs) in their everyday lives, including travel, to a greater extent than older generations. As ICT-driven travel-based multitasking influences travelers' experience and satisfaction in various ways, millennials are expected to be affected at a greater scale. Still, to our knowledge, no previous studies have specifically focused on the impact of travel multitasking on travel behavior and the value of travel time (VOTT) of young adults. To address this gap, we use an original dataset collected among Northern California commuters $(N=2216)$ to analyze the magnitude and significance of individual and household-level factors affecting commute mode choice. We estimate a revealed-preference mode choice model and investigate the differences between millennials and older adults in the sample. Additionally, we conduct a sensitivity analysis to explore how incorporation of explanatory factors such as attitudes and propensity to multitask while traveling in mode choice models affects coefficient estimates, VOTT, and willingness to pay to use a laptop on the commute. Compared to nonmillennials, the mode choice of millennials is found to be less affected by socio-economic characteristics and more strongly influenced by the activities performed while traveling. Young adults are found to have lower VOTT than older adults for both in-vehicle $(15.0 \%$ less) and out-of-vehicle travel time ( $15.7 \%$ less), and higher willingness to pay (in time or money) to use a laptop, even after controlling for demographic traits, personal attitudes, and the propensity to multitask. This study contributes to better understanding the commuting behavior of millennials, and the factors affecting it, a topic of interest to transportation researchers, planners, and practitioners.
\end{abstract}

Keywords Mode choice $\cdot$ Multitasking $\cdot$ Value of travel time $\cdot$ Millennials $\cdot$ Information and communication technology (ICT)

Patricia L. Mokhtarian

patmokh@gatech.edu

Extended author information available on the last page of the article 


\section{Introduction}

The impact of activities conducted while traveling, i.e., travel-based multitasking, ${ }^{1}$ has become an emerging topic in travel behavior research in recent years. On one hand, the increased availability of portable and affordable information and communication technology (ICT) devices-including smartphones, tablets, laptops and, most recently, wearables-has prompted the research community to evaluate the significance of multitasking to transportation. ICT plays a constructive role in many areas of transportation demand: for example, affecting trip-making (e.g., overall trip generation, and the specific time of departure), trip experience, mode choice, and some travel characteristics. On the other hand, sustainability and other goals, coupled with the limited financial resources (and political will) available to meet them, have raised high expectations for modest-scale interventions that can help meet such strategic goals, at least partially. As one such intervention, travel-based multitasking promises to make travel time less onerous, and more productive and enjoyable (at least on certain travel modes). Possible effects could include an increased appreciation of the travel experience-a factor that can increase the number of users that are willing to use and/or pay for some modes and services - and measurable changes in mode choice, e.g., switching to public transit where conducting certain activities during a trip is more feasible. Longer-term effects might include changes in residential location and land use, if some individuals are willing to live farther from habitual destinations and do not mind the longer time spent travelling if this time is perceived as less wasted. Alternatively, of course, effects could be negative both personally (such as a perceived "contamination" of previously "private" travel time with expectations for accessibility and productivity; e.g. Pudāne et al. 2019) and societally (such as diminishing the disutility of travel time in automobiles as well as in transit vehicles).

Many opportunities to multitask, independent from the use of ICT devices, have been available to travelers for a long time. More recently, ICT-enabled multitasking has become a common feature associated with the increased availability of modern digital devices. As with many innovations, younger generations are among the early adopters. Accordingly, to the extent that ICT-related travel-based multitasking affects travel behavior, larger impacts can be expected on the travel choices of current young adults, or millennials.

The millennial generation encompasses those who were born between, approximately, 1980 and the end of the 20th century. Millennials are currently the most populous cohort in the United States, and they have long been attracting considerable attention in consumer and travel behavior research. They are commonly dubbed "digital natives", as they were raised in a time in which advanced ICT devices and services were already part of daily life. From the transportation standpoint, this generation is often reported to have lower car ownership, lower per-capita vehicle-miles traveled (VMT), increased interest in urban residential locations, and higher adoption of digital technologies and shared mobility services (Blumenberg et al. 2012). As time progresses, millennials will play a defining role in shaping the travel patterns of the whole society. However, there is some evidence that, as millennials age, their travel behavior is converging with that of older generations (Garikapati

\footnotetext{
${ }^{1}$ While opinions differ, in this paper, consistent with many other studies and the careful typology of Circella et al. (2012), we view the performance of even one activity while traveling as a type of multitasking, in which the secondary activity is conducted simultaneously with (overlaid upon) the primary activity of traveling.
} 
et al. 2016). All of this makes the millennial cohort of particular interest to current travel behavior research.

Thus, this study combines three timely topics: we (1) analyze the impacts of activities conducted while traveling, and in particular the role of activities that rely on the use of ICT; while (2) investigating the transportation choices of millennials, and how they differ from those of previous generations; and (3) studying them through the lens of the value of travel time ${ }^{2}$ (VOTT) and willingness to pay (WTP) for travel multitasking. Our analysis of the travel behavior of millennials and non-millennials is based on a rich dataset that we collected in 2011-2012 from Northern California commuters (the total sample includes more than 2000 respondents). We estimate revealed-preference multinomial logit (MNL) mode choice models segmented by respondents' age cohort, and discuss the impacts of commute and individual characteristics on the utility associated with each available mode.

Several research questions are addressed in this study. How and to what extent does the travel behavior of millennials differ from that of older generations? What variables influence the mode choice of the members belonging to each cohort? Do millennials have different values of travel time and willingness to pay for the ability to conduct activities while commuting (in particular, to use a laptop/tablet ${ }^{3}$ )?

The remainder of the paper is organized as follows. In the "Literature review" section we review the existing literature and summarize previous research that focuses respectively on the analysis of the impact of activities conducted while traveling, the estimation of the value of travel time, and the travel behavior of millennials. The "Sample description: a generational portrait of millennials" section describes the study sample, including differences between millennials and non-millennials. The next section presents the mode choice models, and discusses the main significant explanatory variables. In the "Value of travel time and willingness to pay for laptop usage" section, for both segments, we calculate the VOTT and the WTP for using a laptop/tablet, treating the latter as illustrative of ICT-based productive activities conducted while traveling. The "Sensitivity analysis" section presents a sensitivity analysis for WTP and VOTT. In the "Discussion and conclusions" section, we conclude by discussing the findings and their significance for present and future travel demand.

\section{Literature review}

This paper aims to bring together three topics: the impact of activities while traveling on mode choice, the estimation of WTP and VOTT, and the analysis of the travel behavior of millennials. Each of these areas has its own stream of well-developed literature that rarely intersects with the others. ${ }^{4}$ To the best of our knowledge, no study has investigated all three

\footnotetext{
${ }^{2}$ Following the discussion in Daly and Hess (2019), we opt for the term "value of travel time" instead of "value of travel time savings".

3 The survey analyzed in this study combined laptops, netbooks, and tablets into a single category. In view of the ephemeral nature of netbooks, for brevity we will refer to the category as "laptop/tablet" throughout.

${ }^{4}$ VOTT is often obtained from a mode choice model, so there is necessarily some overlap between the first two topics, as evidenced in the following discussion. We allocated such studies to one topic or the other, depending on our judgment of whether the primary focus of the study was on (1) activities while traveling, with VOTT offering one mechanism by which the effects of travel multitasking were analyzed the "Impact of activities while traveling on mode choice" subsection; or (2) a VOTT analysis, with travel multitasking offering one explanation for differences or changes in VOTT the "Variations in value of travel time estimates" subsection.
} 
of these subjects together. Therefore, in the remainder of this section, we briefly highlight some previous research on each of these topics, respectively.

\section{Impact of activities while traveling on mode choice}

The research community's interest in the influence of travel-based multitasking on travel behavior has been on the rise throughout the past several years. The conceptual grounds for the impact of multitasking were set forth by DeSerpa (1973), Lyons and Urry (2005), Watts and Urry (2008), and Gripsrud and Hjorthol (2012). Several empirical studies have followed, focusing in particular on (1) the patterns of activities performed while traveling (e.g. Ohmori and Harata 2008); (2) the number of activities performed while traveling, controlling for socio-economic and mode attributes (e.g. Zhang and Timmermans 2010; Tang et al. 2018); (3) the impact of travel-based multitasking on the subjective evaluation of trip experience (Ettema et al. 2012; Susilo et al. 2012; Rhee et al. 2013; Rasouli and Timmermans 2014; Mokhtarian et al. 2015; Shaw et al. 2019; Singleton 2018); and (4) the influence of a multitasking-friendly travel experience on mode choice (Zheng et al. 2016; Malokin et al. 2019). Keseru and Macharis (2018) have compiled a comprehensive review of travel multitasking studies to date.

Recently, Frei et al. (2015) used data from 336 Chicago-area riders to model the engagement in multitasking activities while riding public transit. Among several interesting findings, travel-based multitasking was found to be associated with a better travel experience by allowing saving time and increasing pleasure (e.g., reading a book). Further, an activity (e.g., listening to music) can be used to keep a passenger's mind off the trip.

In our previous work, similarly to Frei et al. (2015), Berliner et al. (2015) analyzed the factors behind the engagement in travel multitasking, separately by the distinctive modes that are used, and distinguishing productive from hedonic, and ICT-based from non-ICTbased activities. Building on the findings in Berliner et al. (2015), the authors of the current paper built a revealed-preference MNL mode choice model where individual-specific travel multitasking propensities were found to have significant, albeit modest, effects on mode choice (Malokin et al. 2019).

To the best of our knowledge, there has been no research that has specifically focused on the travel-based multitasking behavior of millennials. However, several studies that investigated various dimensions associated with travel multitasking used age as a predictive factor. For example, Frei et al. (2015) showed that young adults used ICT devices more actively than older transit users. Susilo et al. (2012) found that young adults of ages 16-25 years were more likely both to use their time beneficially while traveling on a train, and also to consider their commute as wasted time. Mokhtarian et al. (2015) showed that the French Millennial generation was more inclined to evaluate their trips as mentally and physically tiring, and unpleasant, than older generations.

The influence of the activities conducted while traveling on VOTT has also been little studied (although often speculated), to date. In an early stated-preference study, Ettema and Verschuren (2007) demonstrated that age and polychronicity (preference for multitasking) influenced VOTT: younger travelers (unexpectedly) had higher VOTT (by 78\%) than older ones; and the VOTT of monochronic commuters was $32 \%$ higher than that of polychronic ones, suggesting that multitasking preference decreased VOTT. The type of activities conducted while traveling also played a role in determining the VOTT: listening to music tended to lower it by $69 \%$, while reading increased VOTT by $36 \%$. Ettema and Verschuren (2007) illustrated the importance of travel-based multitasking in VOTT calculations by a 
sensitivity analysis. Accounting for monochronicity could increase VOTT by as much as $351 \%$; and factoring in activities while traveling additionally changed VOTT between -59 and $+46 \%$ compared to the base model with no multitasking effects. However, the applicability of the study results is constrained by a number of factors: (1) the limited number and the technological scope of the presented activities, (2) the stated-preference study design, and (3) the inability to evaluate possible mode shifts.

In another study of the influence of activities while traveling on VOTT, Varghese and Jana (2018) employed revealed-preference trip-diary data to estimate conventional (i.e., not containing attitudes) MNL and mixed MNL models separately for travel multitaskers and their opposites. Comparisons of the resulting VOTT estimates were used to quantify the effects of travel multitasking. They found that, on average, multitasking reduces VOTT by $26 \%$, while some of the activities, such as eating and listening to music, are associated with higher VOTT.

\section{Variations in value of travel time estimates}

Willingness to pay (WTP) measures a marginal rate of substitution between two attributes. The VOTT is a special case of willingness to pay-measuring the substitution rate between travel time and travel cost-which is widely used in numerous economic applications that involve evaluating, predicting, and improving the effectiveness of transportation systems in channeling goods and people. Unsurprisingly, the diverse set of attributes of the system itself, the actors involved, and the relationships among them define quite a range of variations in the estimated VOTT. A few extensive meta-analyses and literature reviews have been published in the literature, identifying the main sources of variation in VOTT. Table 1 summarizes the most common causes of variability in VOTT.

In particular, two meta-analyses (Gunn 2001; Hensher and Wang 2016) found that conducting productive activities while traveling reduced VOTT. Both studies considered only business trip purposes and specifically excluded commuting and personal trips from the estimation of the impact on VOTT of productive activities while traveling. Gunn (2001) attributed a 23\% decrease in VOTT between 1988 and 1997 among Dutch train business travelers to the improved in-car experience and diffusion of "laptop-computers", whereas Hensher and Wang (2016) estimated that productive and leisure activities while traveling lowered VOTT for business travelers by $35 \%, 59 \%$, and $42 \%$ for car, train, and bus respectively.

Rich and Vandet (2019) specifically analyzed Danish travel survey datasets (2006-2016) to assess the evolution of VOTT during a time interval that saw the proliferation of mobile ICT applications, using a pooled cross-sectional model to show the heterogeneity of VOTT with respect to economic volatility, personal disposable income, and congestion. They hypothesized that ICT-enabled activities while traveling would contribute to lowering VOTT, but the net impact of multiple competing influences was to increase it by about $10 \%$ across the decade studied, "although in recent years there is a declining tendency" (p. 158).

In an attempt to evaluate VOTT as the difference between the opportunity cost of time (i.e., the cost of forgoing activities that compete with traveling for time) and any utility accruing from the time spent on activities while traveling, Kouwenhoven and de Jong (2018) used a 2009-2011 sample of 822 Dutch travelers to analyze their stated-preference responses on the perceived trip time usefulness with respect to changes in travel time and availability of ICT devices during travel. As expected, they found that travelers who find trip shortening useful (i.e., who place a greater value on activities outside the trip) had 
Table 1 Causes of variability in VOTT

\begin{tabular}{|c|c|c|}
\hline \multirow[t]{2}{*}{ Variable } & \multicolumn{2}{|l|}{ Influence on VOTT } \\
\hline & ... Positive & ... Negative \\
\hline \multicolumn{3}{|l|}{ Trip purpose } \\
\hline Business & $\begin{array}{l}\text { Abrantes and Wardman (2011) } \\
\text { Zamparini and Reggiani (2007) }\end{array}$ & \\
\hline Commute & Abrantes and Wardman (2011) & \\
\hline Leisure & & Abrantes and Wardman (2011) \\
\hline \multicolumn{3}{|l|}{ Trip mode } \\
\hline Bus & & $\begin{array}{l}\text { Abrantes and Wardman (2011) } \\
\text { Shires and de Jong (2009) }\end{array}$ \\
\hline Rail & Abrantes and Wardman (2011) & \\
\hline Car & Abrantes and Wardman (2011) & \\
\hline \multicolumn{3}{|l|}{ Distance } \\
\hline & $\begin{array}{l}\text { Abrantes and Wardman (2011) } \\
\text { Shires and de Jong (2009) } \\
\text { Gunn (2001) }\end{array}$ & \\
\hline \multicolumn{3}{|l|}{ Data collection method } \\
\hline Revealed preference & $\begin{array}{l}\text { Abrantes and Wardman (2011) } \\
\text { Brownstone and Small (2005) }\end{array}$ & \\
\hline Stated preference & & Shires and de Jong (2009) \\
\hline \multicolumn{3}{|l|}{ Income/GDP per capita } \\
\hline & $\begin{array}{l}\text { Abrantes and Wardman (2011) } \\
\text { Shires and de Jong (2009) } \\
\text { Gunn (2001) }\end{array}$ & \\
\hline \multicolumn{3}{|l|}{ Trip attributes } \\
\hline Congestion & Abrantes and Wardman (2011) & \\
\hline Transit delays & Abrantes and Wardman (2011) & \\
\hline Transit headway & & Abrantes and Wardman (2011) \\
\hline Tolls & & Abrantes and Wardman (2011) \\
\hline \multicolumn{3}{|l|}{ Locale } \\
\hline Non-Europe & & Shires and de Jong (2009) \\
\hline \multicolumn{3}{|l|}{ Activities while traveling } \\
\hline Productive & & $\begin{array}{l}\text { Gunn (2001) } \\
\text { Hensher and Wang (2016) }\end{array}$ \\
\hline
\end{tabular}

a VOTT $15 \%$ higher than those who did not. Similarly, those who reported being able to spend their travel time usefully had a 14-26\% lower VOTT. Unexpectedly, however, they also found that travelers who had a mobile phone, computing device, or music player available to them exhibited a 10-20\% increase in VOTT over those who did not have these ICT devices. The authors attempted to explain such a counterintuitive result by suggesting that travelers with ICT might be of higher income and busier.

An important series of contributions to the study of VOTT in the context of activities while traveling can be traced to the seminal work of Jara-Diaz and Guevara (2003). They highlight (p. 32) the decomposition of "the value of saving time in the ith activity" (say, travel, i.e. VOTT) into "the value of doing something else [the value of leisure, 
or $\mathrm{VoL}]$ minus the value of assigning time to that particular activity (because it is being reduced)" - in our case, the value of time assigned to travel (VTAT). In other words, VOTT $=$ VoL - VTAT. Following this decomposition, Hössinger et al. (2020) empirically quantify the value of leisure $(\mathrm{VoL})$ - i.e. the value of expending more than the minimum time required on an activity - and then, using estimates of VOTT obtained by Schmid et al. (2019) from the same 2015 dataset of Austrian workers, compute the value of time assigned to travel (VTAT), i.e. the (dis)utility an individual assigns to travel time itself. From this they analyze how VTAT varies across mode and user characteristics. Consistent with expectations, VTAT is universally negative for walk, bicycle, and car, but is generally positive and averages to a small positive value for transit. The authors conclude that this difference is likely attributable to the quality of Austrian transit, and to the ability to perform other activities while traveling on that mode.

Finally, two recent stated preference studies in France investigate VOTT from the perspective of travel time usage. Nathan et al. (2019, p. 158) analyzed the impact of connectivity to mobile phone/internet networks on VOTT for a sample of 501 Paris residents, finding that "the values ascribed to better connectivity are higher when [public transport] users perform various tasks with smartphones or tablets during their trips". Bouscasse and de Lapparent (2019) estimated an integrated choice and latent variable model for 1120 French commuters to find that comfort and positive perception decrease VOTT by $12-17 \%$ when traveling by train. "Comfort" is a function of the perceived use of travel time during the trip, among other variables, and accordingly, "the VOT[T] decreases as the perception of a worthwhile travel time increases" (p. 380).

Historically, the range of estimated VOTT has been wide. For example, in a comparative study Zamparini and Reggiani (2007) reported the range of VOTT, measured as a percentage of the wage rate, to be as low as 13\% (Talvittie 1972) and as high as 145\% (Guttman 1975) for commuting by car in the U.S. ${ }^{5}$

\section{Travel behavior of millennials}

As millennials are coming of age and gaining a larger share of total travel in the U.S., researchers have become increasingly interested in the travel behavior of this cohort. In particular, researchers have been looking for factors that can account for the (at least temporary) decline in per-capita car travel observed in many developed nations since the beginning of the new millennium [but with a rebound observed beginning in 2015, with new record highs in VMT, if not yet VMT per capita, in the US through 2019 (FHWA 2020)]. One controversial study (Bastian et al. 2016, 2017; Wadud and Baierl 2017) suggests that economic factors such as fuel prices and gross domestic product can adequately explain the observed trend changes; this finding has been largely corroborated by Stapleton et al. (2017). In several other studies, however, millennials have been attributed an important role in explaining the reduced travel volumes through their decreased and delayed driving licensure (Blumenberg et al. 2012; Sivak and Schoettle 2012; Kuhnimhof et al. 2012; Delbosc and Currie 2013); shifts to non-automobile modes (Kuhnimhof et al. 2012); economic hardships, especially connected to employment (Blumenberg et al. 2012; Kuhnimhof et al.

\footnotetext{
5 Our estimations in the fifth section, "Value of travel time and willingness to pay for laptop usage" fall near the lower end of this range at about $19 \%$ of the hourly wage, which is crudely inferred from the annual household income.
} 
2012); increased preferences for urban living (Blumenberg et al. 2012; Kuhnimhof et al. 2012); changes in social norms (Hopkins and Stephenson 2015); and adoption of ICTs, whether for travel substitution (Sivak and Schoettle 2012), for travel inducement (Blumenberg et al. 2012; Hopkins and Stephenson 2015), or, even, as new vanity/status objects (Tully 2011).

Blumenberg et al. (2012), by analyzing National Household Travel Survey (NHTS) data via a series of binary logit models, revealed that driving alone to work was positively associated with higher income, while taking transit was more prominent among the "boomerang" youth (i.e., those who returned to live with their parents). Interestingly, their study shows that non-income-related socio-economic characteristics, while having an effect on non-millennial commute mode choice, had none on young adults' choices. McDonald (2015) also used NHTS data to show that millennials' decrease in VMT comes from fewer automobile trips, rather than a shift to alternative modes. In other studies, Shannon et al. (2006), Kerr et al. (2010), and Zhou (2012) used convenience samples of university students to assess, mostly descriptively, millennials' reasons for choosing a particular mode and flexibility towards changing their choice.

To the best of our knowledge, there have been no prior studies that link together the willingness to pay for travel time and ICT-induced mode choices among millennial versus non-millennial commuters. Synthesizing key findings from the three streams of literature reviewed, however, we make the following informed speculation: (1) since the productive use of travel time has been found to lower VOTT, (2) since ICT enables a broader spectrum of ways to use travel time productively, and (3) since millennials are likely to be more inclined than their elders to use ICT while traveling, millennials will have a lower VOTT than older commuters.

\section{Sample description: a generational portrait of millennials}

The empirical analysis of this paper is based on data collected from a survey administered in 2011-2012 in Northern California (Neufeld and Mokhtarian 2012). The survey consisted of nine sections that canvassed such topics as general lifestyle and transportation opinions, personality characteristics, multitasking preferences, time use and waiting attitudes, travel mode perceptions, commuting and travel multitasking behavior, and socioeconomic attributes. Paper questionnaires and invitations to take an online equivalent were distributed in transit vehicles and at transit stops, placed under windshield wipers of vehicles parked in carpool-reserved spots, sent to a large commute alternatives email list and other lists, sent to the members of a paid opinion panel, and mailed to a random selection of residential addresses. This approach enabled us to collect data from various segments of the population and different geographies, and in particular allowed for adequate numerical representation of less-often chosen modes. Specifically, we purposefully oversampled modes other than driving alone. ${ }^{6}$ Only respondents that were 18 years old and above, who commuted to work or school at least once a month, were invited to participate in the study. Millennials were defined as those born in 1980 or later (in view of the age restriction, the

\footnotetext{
${ }^{6}$ As can be seen from Table 2, had the sample proportionally represented mode shares by cohort, we would have had only 12 and 22 bicyclists and 4 and 12 commuter rail users among millennials and non-millennials, respectively (instead of 84, 107, 32, and 143 in the actual sample)_far too few for stable parameter estimation.
} 
Table 2 Selected socio-economic characteristics of the unweighted and weighted sample, distinguishing millennial and non-millennial segments

\begin{tabular}{|c|c|c|c|c|c|c|c|c|}
\hline \multirow[t]{2}{*}{ Characteristic } & \multicolumn{4}{|c|}{ Unweighted dataset } & \multicolumn{4}{|c|}{ Weighted dataset ${ }^{\mathrm{a}}$} \\
\hline & \multicolumn{2}{|c|}{$\begin{array}{l}\text { Millennials } \\
(496)\end{array}$} & \multicolumn{2}{|c|}{ Non-Millennials (1720) } & \multicolumn{2}{|c|}{$\begin{array}{l}\text { Millennials } \\
(525)\end{array}$} & \multicolumn{2}{|c|}{$\begin{array}{l}\text { Non-Millennials } \\
\text { (1691) }\end{array}$} \\
\hline \multicolumn{9}{|l|}{ Gender $(N=2196)$} \\
\hline Female & 315 & $64.3 \%$ & 1045 & $61.3 \%$ & 351 & $67.6 \%$ & 1054 & $62.8 \%$ \\
\hline \multicolumn{9}{|l|}{ Ethnicity $^{b}(N=2216)$} \\
\hline White & 309 & $62.3 \%$ & 1157 & $67.3 \%$ & 315 & $60.0 \%$ & 1112 & $65.8 \%$ \\
\hline Black & 13 & $2.6 \%$ & 69 & $4.0 \%$ & 17 & $3.2 \%$ & 61 & $3.6 \%$ \\
\hline Asian & 98 & $19.8 \%$ & 232 & $13.5 \%$ & 113 & $21.5 \%$ & 238 & $14.1 \%$ \\
\hline Hispanic & 51 & $10.3 \%$ & 121 & $7.0 \%$ & 52 & $9.9 \%$ & 111 & $6.6 \%$ \\
\hline \multicolumn{9}{|c|}{ Education level $(N=2216)$} \\
\hline High school & 11 & $2.2 \%$ & 55 & $3.2 \%$ & 11 & $2.0 \%$ & 63 & $3.8 \%$ \\
\hline College & 273 & $55.0 \%$ & 949 & $55.2 \%$ & 319 & $58.3 \%$ & 968 & $58.0 \%$ \\
\hline Graduate work & 212 & $42.8 \%$ & 716 & $41.6 \%$ & 174 & $37.6 \%$ & 682 & $38.9 \%$ \\
\hline \multicolumn{9}{|l|}{ Occupation $(N=2209)$} \\
\hline Professional & 181 & $36.5 \%$ & 927 & $53.9 \%$ & 195 & $37.1 \%$ & 868 & $51.3 \%$ \\
\hline Student & 154 & $31.1 \%$ & 34 & $2.0 \%$ & 134 & $25.5 \%$ & 27 & $1.6 \%$ \\
\hline Manager & 48 & $9.7 \%$ & 325 & $18.9 \%$ & 60 & $11.4 \%$ & 338 & $20.0 \%$ \\
\hline Sales & 27 & $5.4 \%$ & 52 & $3.0 \%$ & 29 & $5.5 \%$ & 64 & $3.8 \%$ \\
\hline Service & 11 & $2.2 \%$ & 40 & $2.3 \%$ & 16 & $3.1 \%$ & 48 & $2.8 \%$ \\
\hline Clerical & 62 & $12.5 \%$ & 276 & $16.1 \%$ & 75 & $14.3 \%$ & 273 & $16.1 \%$ \\
\hline Other & 10 & $2.0 \%$ & 56 & $3.3 \%$ & 14 & $2.7 \%$ & 69 & $4.1 \%$ \\
\hline \multicolumn{9}{|c|}{ Annual HH income $(N=2132)$} \\
\hline Less than $\$ 25,000$ & 85 & $17.8 \%$ & 42 & $2.5 \%$ & 62 & $12.3 \%$ & 47 & $2.9 \%$ \\
\hline$\$ 25,000$ to $\$ 49,999$ & 105 & $21.9 \%$ & 207 & $12.5 \%$ & 135 & $26.7 \%$ & 215 & $13.2 \%$ \\
\hline$\$ 50,000$ to $\$ 74,999$ & 93 & $19.4 \%$ & 342 & $20.7 \%$ & 96 & $19.0 \%$ & 340 & $20.9 \%$ \\
\hline$\$ 75,000$ to $\$ 99,999$ & 80 & $16.7 \%$ & 333 & $20.2 \%$ & 88 & $17.4 \%$ & 337 & $20.7 \%$ \\
\hline$\$ 100,000$ to $\$ 124,999$ & 61 & $12.7 \%$ & 295 & $17.8 \%$ & 69 & $13.7 \%$ & 266 & $16.3 \%$ \\
\hline$\$ 125,000$ or more & 55 & $11.5 \%$ & 434 & $26.3 \%$ & 55 & $10.9 \%$ & 425 & $26.1 \%$ \\
\hline \multicolumn{9}{|c|}{ Commute distance $(N=2216)$} \\
\hline Average, miles & \multicolumn{2}{|c|}{18.484} & \multicolumn{2}{|c|}{21.766} & \multicolumn{2}{|l|}{18.226} & \multicolumn{2}{|c|}{18.555} \\
\hline \multicolumn{9}{|c|}{ Primary commute mode $(N=2216)$} \\
\hline Biking & 84 & $16.9 \%$ & 107 & $6.2 \%$ & 12 & $2.3 \%$ & 22 & $1.3 \%$ \\
\hline Commuter rail & 32 & $6.5 \%$ & 143 & $8.3 \%$ & 4 & $0.8 \%$ & 12 & $0.7 \%$ \\
\hline Transit & 125 & $25.2 \%$ & 519 & $30.2 \%$ & 47 & $9.0 \%$ & 133 & $7.9 \%$ \\
\hline Shared ride & 83 & $16.7 \%$ & 269 & $15.6 \%$ & 83 & $15.8 \%$ & 218 & $12.9 \%$ \\
\hline Driving alone & 172 & $34.7 \%$ & 682 & $39.7 \%$ & 379 & $72.2 \%$ & 1306 & $77.2 \%$ \\
\hline \multicolumn{9}{|c|}{ Population commute mode shares $(N=4,119,532)$} \\
\hline Biking & 21,830 & $2.2 \%$ & 41,347 & $1.3 \%$ & & & & \\
\hline Commuter rail & 7717 & $0.8 \%$ & 21,787 & $0.7 \%$ & & & & \\
\hline Transit & 88,062 & $8.9 \%$ & 248,619 & $7.8 \%$ & & N/A & & \\
\hline Shared ride & 156,576 & $15.9 \%$ & 409,727 & $12.9 \%$ & & & & \\
\hline Driving alone & 710,934 & $72.2 \%$ & $2,448,824$ & $77.2 \%$ & & & & \\
\hline
\end{tabular}

${ }^{a}$ Weights were calculated based on population commute mode shares (separately for millennials and nonmillennials) for 16 Northern California counties, available from the Census Transportation Planning Products, http://ctpp.transportation.org/Pages/default.aspx, ACS 2006-2010 data

${ }^{\mathrm{b}}$ Categories are not mutually exclusive 
latest birth year was 1994). The final sample size for this study is 2216. Selected socioeconomic descriptive statistics are presented in Table 2. To correct for the sampling bias in our essentially choice-based sample and produce consistent estimates of the mode choice model coefficients (specifically the alternative specific constants; Ben-Akiva and Lerman 1985), the sample was weighted to approximately represent population commute mode shares; the model and subsequent results are based on the weighted sample.

As Table 2 shows, socio-economic descriptive statistics for the weighted sample are rather similar to the corresponding figures for the unweighted data. In other words, the patterns in the sample are not heavily affected by weighting.

Along with socio-economic attributes, the survey collected rich attitudinal and behavioral transportation-related data that can be used in deeper investigation of relationships and patterns within the sample. Attitudes were represented by answers to statements reported on an ordered scale (e.g., ranging from "strongly disagree" to "strongly agree") with three or five levels. Since latent constructs were purposefully tapped through multiple attitudinal statements (e.g., technological affinity can reveal itself through, among other ways, a preference for having newer ICT gadgets and a desire to introduce them to friends), factor analyses were performed to uncover the higher-level attitudinal concepts. Regression scores were created for each person on each factor, as a linear combination of the responses to individual statements, where the weight given to each statement is proportional to the strength of association of that statement with the underlying factor. Travel multitasking was reported for the chosen primary commute mode and encompassed questions (binary variables) of what things commuters carried with them, in which activities they engaged, and what benefits and disadvantages they received from these activities. Objective mode attributes for chosen and unchosen modes, such as travel time and travel cost, were obtained through Google Maps and Bing Maps APIs by using the reported addresses (translated to $\mathrm{XY}$ coordinates) of residential and work locations. More detailed discussions of the factor analyses of attitudinal variables, travel multitasking behavior, and the collection of the objective mode attributes can be found in Malokin et al. (2019).

Millennials in our sample also resemble those in more representative national sociological studies (e.g., Pew Research Center 2014). They are more ethnically diverse than previous generations (see Table 3); however, their share of immigrants is lower. Young adults are somewhat better educated $(75.8 \%$ of millennials and $70.1 \%$ of non-millennials have at least a bachelor's degree). They have a lower average household income $(\$ 73,000$ and \$101,000 for millennials and non-millennials, respectively), and their access to betterpaying occupations is limited. The younger generation, on average, has lower bicycle ownership, and fewer of its members possess a driver's license.

Analysis of variance (ANOVA) results (Table $3^{7}$ ) identified significant differences between the two segments with respect to various attitudes, personality traits and preferences. Millennials are found to be more technologically oriented and savvy, adopting novel gadgets sooner and using them at a greater scale: presence of ICT devices and their usage while traveling were more likely to be reported by younger adults. ${ }^{8}$ Millennials,

\footnotetext{
7 No significant differences between segments were found on numerous other variables tested, including shares of blacks; sales, production, service, and clerical occupations; presence of children under 6; household size; number of household vehicles; limitations on driving, taking transit, walking, and bicycling; and multiple attitudes and perceptions, including polychronicity.

${ }^{8}$ It is interesting to note that no type of activity while traveling was more likely to be performed by nonmillennials. Most behaviors that are commonly associated with ICT devices, and other basic activities, were significantly more likely to be performed by millennials: watching video, using internet, using a non-smartphone, using a smartphone, sending SMS, using a laptop/tablet, navigating with GPS, thinking/planning, playing electronic games, reading electronic materials, eating, resting, grooming, watching scenery, and
} 
Table 3 Significant variations in socio-economic attributes and attitudes between weighted millennial and non-millennial segments

\begin{tabular}{|c|c|c|c|c|c|}
\hline Variable & Variable type & $\begin{array}{l}\text { Millennials } \\
(\mathrm{N}=525)\end{array}$ & $\begin{array}{l}\text { Non-millennials } \\
(\mathrm{N}=1691)\end{array}$ & $\mathrm{F} / \chi^{2}$ statistic $^{\mathrm{a}}$ & Signif. \\
\hline Female & Binary & 0.68 & 0.63 & 3.990 & $0.046 * *$ \\
\hline \multicolumn{6}{|l|}{ Ethnicity } \\
\hline White & Binary & 0.60 & 0.66 & 6.035 & $0.014 * *$ \\
\hline South Asian & Binary & 0.02 & 0.01 & 5.069 & $0.024 * *$ \\
\hline East Asian & Binary & 0.20 & 0.13 & 12.818 & $0.000^{* * *}$ \\
\hline Hispanic & Binary & 0.10 & 0.07 & 6.561 & $0.010 * *$ \\
\hline Immigrant & Binary & 0.21 & 0.25 & 4.373 & $0.037 * *$ \\
\hline Education & Ordinal & - & - & 87.383 & $0.000 * * *$ \\
\hline Annual HH income & Ordinal & - & - & 153.726 & $0.000 * * *$ \\
\hline \multicolumn{6}{|l|}{ Occupation } \\
\hline Professional & Binary & 0.37 & 0.51 & 32.232 & $0.000^{* * *}$ \\
\hline Student $^{\mathrm{b}}$ & Binary & 0.26 & 0.02 & 341.052 & $0.000^{* * *}$ \\
\hline Manager & Binary & 0.11 & 0.20 & 19.689 & $0.000 * * *$ \\
\hline HH bicycle ownership & Count & 1.58 & 2.13 & 41.552 & $0.000 * * *$ \\
\hline Has driver's license & Binary & 0.98 & 0.99 & 8.476 & $0.004^{* * *}$ \\
\hline \multicolumn{6}{|l|}{ General attitudes (factor scores) } \\
\hline Pro-technology & Continuous & 0.27 & -0.06 & 40.090 & $0.000^{* * *}$ \\
\hline Pro-active modes ${ }^{\mathrm{c}}$ & Continuous & -0.12 & -0.26 & 8.226 & $0.004^{* * *}$ \\
\hline Pro-transit $^{\mathrm{c}}$ & Continuous & -0.46 & -0.34 & 6.828 & $0.009^{* * *}$ \\
\hline Time pressure-reality & Continuous & 0.20 & -0.04 & 24.448 & $0.000^{* * *}$ \\
\hline Time pressure-preference & Continuous & 0.13 & -0.05 & 12.354 & $0.000 * * *$ \\
\hline \multicolumn{6}{|l|}{ Personality traits (factor scores) } \\
\hline Extraverted & Continuous & 0.18 & -0.08 & 26.590 & $0.000 * * *$ \\
\hline Organized & Continuous & -0.08 & 0.07 & 8.789 & $0.003^{* * *}$ \\
\hline Frustrated & Continuous & 0.26 & -0.05 & 39.465 & $0.000^{* * *}$ \\
\hline Responsible & Continuous & -0.04 & 0.12 & 10.305 & $0.001^{* * *}$ \\
\hline Risk-taker & Continuous & -0.17 & 0.03 & 16.382 & $0.000^{* * *}$ \\
\hline Leader & Continuous & 0.35 & -0.09 & 83.088 & $0.000^{* * *}$ \\
\hline Like to move fast ${ }^{\mathrm{d}}$ & Ordinal & 0.20 & -0.09 & 35.558 & $0.000^{* * *}$ \\
\hline \multicolumn{6}{|c|}{ Multitasking preferences (factor scores) } \\
\hline $\begin{array}{l}\text { Background noise } \\
\text { multitasking }\end{array}$ & Continuous & 0.25 & 0.04 & 18.719 & $0.000^{* * *}$ \\
\hline "Activity" multitasking & Continuous & 0.16 & 0.04 & 5.632 & $0.018 * *$ \\
\hline Normative multitasking & Continuous & 0.12 & -0.03 & 21.085 & $0.000^{* * *}$ \\
\hline (Work) "task" monotasking & Continuous & 0.11 & -0.09 & 17.017 & $0.000^{* * * *}$ \\
\hline
\end{tabular}

$* * *, * *$ Significant at $1 \%, 5 \%$

${ }^{\mathrm{a}}$ For binary, ordinal, and count variables, a $\chi^{2}$ test was used; for continuous variables, an $\mathrm{F}$ test was used

${ }^{\mathrm{b}}$ Only working students are included in the sample

'Ordinarily, the sample mean of standardized factor scores would equal zero, and thus the means of each subsample (millennials and non-millennials) would have opposite signs (if different from zero). In the present instance, the sample mean may differ from zero for two reasons: (1) the current sample is a subset of the sample that was used for the factor analyses $(\mathrm{N}=2849)$, and (2) weighting could substantially alter the contribution of each observation

${ }^{\mathrm{d}}$ Standardized single item 
comparatively, feel more favorably toward active modes of transportation, like walking and bicycling. Counter to stereotype, however, they have more negative attitudes about transit than older commuters do.

Among personality traits, millennials are more extraverted, impatient, and perfectionistic (the last two traits load on the Frustrated factor). On the other hand, compared to the older generations, millennials are less organized and responsible-stereotypical traits of every emerging generation. On a surprising note, our data shows millennials to accept less risk and be less aggressive (Risk-taker factor) than non-millennials, perhaps influenced by coming of age during a global economic recession.

With regard to multitasking (Table 4), millennials are more willing to accept audiovisual background stimuli (e.g., radio or TV) than older generations. They also think that multitasking should be practiced by other people (normative beliefs); however, when it comes to their own behavior, they prefer to concentrate on one work-related "task" at a time but accept non-specified "activity" multitasking. ${ }^{9}$ When they travel, millennials more often than non-millennials reported carrying a smartphone, laptop, and MP3 player, among other things, while non-millennials more often than millennials reported carrying a newspaper, magazine, simple cellphone, or tablet (Table 4). Young adults reported several disadvantages of travel-based multitasking more often than their elders did, which could be an indication of their experience with a wider range of activities (including ICT-enabled activities) on the go.

Table 5 presents the mode-specific perception factor scores and propensity to use a laptop on the commute by segment, together with the statistical tests of difference between segment. On average, millennials have more favorable views of the comfort of bicycling, and less favorable views of the comfort of commuter rail and transit, than non-millennials. Millennials also have more favorable views of the benefit/cost of ridesharing, and less favorable views on all four perceptual dimensions (convenience, benefit/cost, comfort, and ability to multitask) for driving alone. Consistent with expectation, they have substantially higher propensities to use a laptop on commuter rail and transit.

Because of their volume, statistics for the objective travel characteristics by mode and cohort are presented in Tables 9 and 10 of the Appendix, and correlations among those characteristics by mode and cohort are presented in Tables 11, 12, 13 and 14 (the bicycle mode is omitted from the correlation tables because its costs and out-of-vehicle travel times are assumed to be 0). On average, millennials have lower travel costs and times for every mode, although the differences are generally small, even when statistically significant.

\footnotetext{
Footnote 8 (continued)

daydreaming. The remaining activities measured were performed at statistically similar rates by millennials and non-millennials: listening to audio, talking to friends, talking to strangers, navigating with a map, playing non-electronic games, writing paper materials, writing electronic materials, reading paper materials, and exercising.

9 The survey included all items associated with the two most-commonly-used polychronicity scales: the Inventory of Polychronic Values (IPV; Bluedorn et al. 1999) and the Polychronic-Monochronic Tendency Scale (PMTS; Lindquist and Kaufman-Scarborough, 2007). Items associated with the IPV tended to use the terms "task" and "work", while those associated with the PMTS tended to use the word "activity", with no purpose specified. Whether representing a semantic artifact or a genuine difference, these two groups of items tended to load on different factors in the factor analysis.
} 
Table 4 Significant variations in travel-multitasking characteristics between weighted millennial and nonmillennial segments

\begin{tabular}{|c|c|c|c|c|c|}
\hline Variable & Variable type & $\begin{array}{l}\text { Millennials } \\
(\mathrm{N}=525)\end{array}$ & $\begin{array}{l}\text { Non-Millennials } \\
(\mathrm{N}=1691)\end{array}$ & $\chi^{2}$ statistic & Sign. \\
\hline \multicolumn{6}{|l|}{ Activities while traveling } \\
\hline Watching video ${ }^{\mathrm{a}}$ & Binary & 0.06 & 0.04 & 7.196 & $0.007 * * *$ \\
\hline Using internet ${ }^{\mathrm{a}}$ & Binary & 0.28 & 0.13 & 61.525 & $0.000^{* * *}$ \\
\hline Talking on phone $\mathrm{e}^{\mathrm{a}}$ & Binary & 0.37 & 0.30 & 8.937 & $0.003^{* * *}$ \\
\hline Using smartphone $^{\mathrm{a}}$ & Binary & 0.48 & 0.26 & 89.108 & $0.000^{* * *}$ \\
\hline Texting $^{\mathrm{a}}$ & Binary & 0.42 & 0.20 & 106.858 & $0.000^{* * *}$ \\
\hline Using a laptop/tablet ${ }^{\mathrm{a}}$ & Binary & 0.10 & 0.05 & 15.571 & $0.000^{* * *} *$ \\
\hline Navigating with GPS ${ }^{a}$ & Binary & 0.18 & 0.10 & 21.737 & $0.000 * * *$ \\
\hline Thinking/planning ${ }^{\mathrm{a}}$ & Binary & 0.83 & 0.74 & 19.677 & $0.000 * * *$ \\
\hline Gaming electronically $^{\mathrm{a}}$ & Binary & 0.09 & 0.05 & 14.889 & $0.000^{* * *}$ \\
\hline Reading electronically ${ }^{\mathrm{a}}$ & Binary & 0.16 & 0.10 & 15.474 & $0.000^{* * *} *$ \\
\hline Eating & Binary & 0.52 & 0.43 & 12.034 & $0.001 * * *$ \\
\hline Resting & Binary & 0.11 & 0.08 & 4.290 & $0.038^{* *} *$ \\
\hline Grooming & Binary & 0.10 & 0.06 & 10.299 & $0.001 * * *$ \\
\hline Watching scenery/people & Binary & 0.54 & 0.49 & 4.030 & $0.045^{* *}$ \\
\hline Daydreaming & Binary & 0.54 & 0.42 & 22.866 & $0.000 * * *$ \\
\hline \multicolumn{6}{|l|}{ Carrying items while traveling } \\
\hline Food & Binary & 0.72 & 0.65 & 6.942 & $0.008 * * *$ \\
\hline Newspaper & Binary & 0.03 & 0.10 & 27.939 & $0.000 * * *$ \\
\hline Magazine & Binary & 0.07 & 0.11 & 8.900 & $0.003 * * *$ \\
\hline Laptop & Binary & 0.26 & 0.17 & 22.017 & $0.000 * * *$ \\
\hline Smartphone & Binary & 0.71 & 0.55 & 46.320 & $0.000 * * *$ \\
\hline "Simple" cell phone & Binary & 0.21 & 0.31 & 19.182 & $0.000 * * *$ \\
\hline Electronic games & Binary & 0.09 & 0.04 & 22.314 & $0.000 * * *$ \\
\hline $\begin{array}{l}\text { Internet-enabled MP3 player (e.g., } \\
\operatorname{iPod}^{\circledR} \text { ) }\end{array}$ & Binary & 0.09 & 0.05 & 12.152 & $0.000 * * *$ \\
\hline "Simple" MP3 player & Binary & 0.18 & 0.09 & 28.602 & $0.000 * * *$ \\
\hline Internet-enabled tablet (e.g., iPad ${ }^{\circledR}$ ) & Binary & 0.03 & 0.05 & 4.230 & $0.040^{* *}$ \\
\hline GPS unit & Binary & 0.24 & 0.18 & 7.012 & $0.008^{* * *}$ \\
\hline No items & Binary & 0.02 & 0.06 & 12.649 & $0.000 * * *$ \\
\hline \multicolumn{6}{|l|}{ Benefits of travel multitasking } \\
\hline Makes unpleasant trip tolerable & Binary & 0.21 & 0.13 & 16.992 & $0.000^{* * *}$ \\
\hline \multicolumn{6}{|l|}{ Disadvantages of travel multitasking } \\
\hline No disadvantages & Binary & 0.45 & 0.63 & 57.212 & $0.000 * * *$ \\
\hline Diminishes enjoyment of activities & Binary & 0.05 & 0.02 & 17.581 & $0.000^{* * * *}$ \\
\hline Creates unsafe distraction & Binary & 0.17 & 0.12 & 9.867 & $0.002 * * *$ \\
\hline Fragments attention & Binary & 0.11 & 0.08 & 7.518 & $0.006^{* * *}$ \\
\hline Takes time away from other things & Binary & 0.18 & 0.09 & 29.762 & $0.000 * * *$ \\
\hline Can't perform activities as well & Binary & 0.13 & 0.10 & 4.488 & $0.034 * *$ \\
\hline $\begin{array}{l}\text { To what extent is commute favorable } \\
\text { for travel multitasking }{ }^{\mathrm{b}}\end{array}$ & Ordinal & 2.45 & 2.36 & 26.497 & $0.000 * * *$ \\
\hline
\end{tabular}

$* * *, * *$ Significant at $1 \%, 5 \%$

${ }^{a}$ Originally, the activity was reported separately for two purposes: work and leisure/personal. For this analysis the purposes were combined

'The variable ranges from "Hardly at all" (=1) to "Almost completely" (=5) 
Table 5 Mode-specific perceptions and propensity to use laptop by weighted millennial and non-millennial segments

\begin{tabular}{|c|c|c|c|c|c|}
\hline Variable & Variable type & $\begin{array}{l}\text { Millennials } \\
(\mathrm{N}=525)\end{array}$ & $\begin{array}{l}\text { Non-millennials } \\
(\mathrm{N}=1691)\end{array}$ & $\mathrm{F} / \chi^{2}$ statistic $^{\mathrm{a}}$ & Signif. \\
\hline \multicolumn{6}{|l|}{ Perceptions } \\
\hline Convenience-bicycle & Continuous & 0.319 & 0.349 & 0.102 & 0.750 \\
\hline Benefit/cost-bicycle & Continuous & 1.416 & 1.547 & 2.567 & 0.110 \\
\hline Comfort-bicycle & Continuous & -0.942 & -1.415 & 16.042 & $0.000 * * *$ \\
\hline $\begin{array}{l}\text { Ability to multitask-bicy- } \\
\text { cle }^{\text {b }}\end{array}$ & Ordinal & -0.681 & -0.715 & 8.324 & 0.080 \\
\hline $\begin{array}{l}\text { Convenience-commuter } \\
\text { rail }\end{array}$ & Continuous & -0.617 & -0.619 & 0.001 & 0.979 \\
\hline Benefit/cost-commuter rail & Continuous & -0.027 & 0.017 & 0.932 & 0.334 \\
\hline Comfort-commuter rail & Continuous & 0.060 & 0.224 & 6.465 & $0.011^{* *}$ \\
\hline $\begin{array}{l}\text { Ability to multitask-com- } \\
\text { muter rail }^{\text {b }}\end{array}$ & Ordinal & 0.077 & 0.059 & 7.299 & 0.121 \\
\hline Convenience-transit & Continuous & -0.743 & -0.749 & 0.034 & 0.853 \\
\hline Benefit/cost-transit & Continuous & 0.142 & 0.108 & 0.909 & 0.340 \\
\hline Comfort-transit & Continuous & -0.501 & -0.331 & 11.599 & $0.001 * * *$ \\
\hline Ability to multitask- transit $^{\mathrm{b}}$ & Ordinal & -0.259 & -0.256 & 4.643 & 0.326 \\
\hline Convenience-shared ride & Continuous & -0.541 & -0.545 & 0.013 & 0.909 \\
\hline Benefit/cost-shared ride & Continuous & 0.121 & 0.043 & 4.928 & $0.027 * *$ \\
\hline Comfort-shared ride & Continuous & 0.118 & 0.114 & 0.009 & 0.924 \\
\hline $\begin{array}{l}\text { Ability to multitask-shared } \\
\text { ride }^{\mathrm{b}}\end{array}$ & Ordinal & -0.209 & -0.285 & 6.719 & 0.152 \\
\hline Convenience-drive alone & Continuous & 1.079 & 1.172 & 8.563 & $0.003 * * *$ \\
\hline Benefit/cost-drive alone & Continuous & -0.696 & -0.522 & 15.341 & $0.000 * * *$ \\
\hline Comfort-drive alone & Continuous & 0.069 & 0.336 & 39.769 & $0.000 * * *$ \\
\hline $\begin{array}{l}\text { Ability to multitask-drive } \\
\text { alone }^{\text {b }}\end{array}$ & Ordinal & 0.343 & 0.423 & 15.407 & $0.004 * * *$ \\
\hline \multicolumn{6}{|l|}{ Propensity to use laptop ${ }^{c}$} \\
\hline Commuter rail & Continuous & 0.157 & 0.126 & 9.571 & $0.002 * * *$ \\
\hline Transit & Continuous & 0.131 & 0.114 & 14.415 & $0.000 * * *$ \\
\hline Shared ride & Continuous & 0.142 & 0.132 & 0.981 & 0.322 \\
\hline Drive alone & Continuous & 0.049 & 0.038 & 11.870 & $0.001 * * *$ \\
\hline
\end{tabular}

$* * * * *$ Significant at $1 \%, 5 \%$

${ }^{\text {a}}$ For ordinal variables, a $\chi^{2}$ test was used; for continuous variables, an $\mathrm{F}$ test was used

${ }^{b}$ Rating of the mode with respect to "ability to do things I need/want while traveling", on a 5-point scale ranging from "very bad" to "very good"

"See the "Mode choice model estimation and analysis" section for an explanation of these variables, which are predicted probabilities. Three people in the full sample reported using a "laptop" (which could include a tablet) on a commute whose primary mode was bicycle (Malokin et al. 2019, footnote 2). This is possible, e.g. by listening to music played through a tablet stored in a backpack, so we retained this empirical evidence by setting the propensity to use laptop while bicycling to 0.01 for everyone. Accordingly, statistical tests on differences between groups could not be computed for this variable 


\section{Mode choice model estimation and analysis}

In this study, we model the choice of primary commute mode. Respondents reported their choice from a set of five alternatives: bicycle, commuter rail, transit (including local bus, express bus, light rail, and metro rail), shared ride (carpool, vanpool, and employer shuttle), and drive alone. The choice set composition is individual-specific and contains two to four alternatives (the upper limit is due to having only four sets of mode perceptions available in each questionnaire); thus, the estimation operates with unequal choice sets.

The explanatory variables included in the model comprise mode-specific objective attributes (in-vehicle and out-of-vehicle travel time, and travel $\cos ^{10}$ ), socioeconomic characteristics (gender, license possession, and ethnicity), individuals' attitudes (mode perceptions, general attitudes, polychronicity), and the mode-specific propensity to use a laptop/tablet. The latter variable was computed as follows. For each mode-activity combination, we formulated a binary logit model using travelers' mode-specific involvement in each activity $(=1$ if reported, $=0$ otherwise), as the dependent variable. Individual characteristics such as socioeconomic attributes, multitasking preferences, general attitudes and personality traits, time use expectations and preferences, and attitudes toward waiting were used as explanatory variables. Each model was calibrated on respondents who chose that mode, and the result was applied to predict the probability of performing that activity on that mode for all respondents, if they were to choose that mode (for additional information, see Berliner et al. 2015 and Malokin et al. 2019). That predicted probability is the propensity to use a laptop/tablet on that mode, which we can view as a proxy for the desire to be productive while traveling. ${ }^{11}$

We divided the sample into two parts (millennials and non-millennials) based on the year of birth of the respondents. Then, we estimated MNL models for each segment and for the whole sample. The three final specifications were kept identical to facilitate comparisons. Where variables did not differ by alternative (namely socioeconomic traits and general attitudes), we allowed their coefficients to differ by each alternative (generally taking driving alone as the reference alternative), and then eliminated terms that were insignificant in all three models. Where variables differed by alternative (namely objective mode characteristics and mode perceptions), we tested alternative-specific coefficients but

\footnotetext{
10 As reported in the companion paper (Malokin et al., 2019) that developed the mode choice model on the pooled sample that served as the starting point for the segmented models of the present study, we experimented with alternative-specific and raw generic specifications of travel cost, but the best fit and most satisfactory results were obtained by specifying generic coefficients for $\ln (\operatorname{cost})$. This is a common transformation of cost in mode choice models, reflecting a diminishing marginal impact of cost on utility (meaning that a unit increase in cost has a smaller incremental disutility when the base cost is large than when it is small).

11 As noted by Malokin et al. (2019, p. 91), "Among 23 reported activities, we selected the propensity to use a laptop, netbook, or tablet computer for work or personal purposes ('use a laptop', hereafter) for inclusion in the mode choice model specification. This decision was based on several reasons. For one thing, conceptually, personal computer usage could be strongly associated with a plethora of productive tasks that commuters would like to undertake to make more valuable use of their travel time (objectively and subjectively). This assumption is corroborated by the data: $61.5 \%$ of the respondents who used laptop reported 'allows me to get more work done' to be among the benefits of the activities they do while commuting. For another thing, an exploratory factor analysis (Malokin et al. 2015) that we developed on the propensities to engage in activities while traveling showed close association between using a laptop and 'writing/editing electronic documents': together with 'thinking/planning' and 'reading electronic documents', they all load on one factor, i.e., 'productive [activities]'. While writing/editing electronic documents could be enabled by a (continuously increasing) variety of technological devices, usually a laptop computer (or a tablet) represents a major gateway for being productive, especially while traveling.".
} 
ultimately preferred generic coefficients in the interests of interpretability and parsimony. Each model was weighted using the population mode shares, as described in the "Sample description" section, to account for (the purposeful) sampling bias, i.e., underrepresenting driving alone commuters and overrepresenting other mode users.

Although we tested more sophisticated model forms (including nested, cross-nested, and generalized nested logit; mixed logit; and latent-class models), none of them proved statistically superior to the MNL model, perhaps an indication of good specification of the latter (see, e.g., Train's admonition (Train 2009, pp. 35-36) that "In a deep sense, the ultimate goal of the researcher is to represent utility so well that the only remaining aspects constitute simply white noise; that is, the goal is to specify utility well enough that a [multinomial] logit model [rather than a more complex specification] is appropriate").

The segmented models for millennials and non-millennials fit the data slightly better than the pooled one $\mathrm{e}^{12}$ but the goodness of fit for all three models is considered strong. All coefficients in the mode choice models have the expected sign and are significant in the pooled model. Consistency with the Independence of Irrelevant Alternatives (IIA) assumption was investigated by conducting Hausman-McFadden tests, and by evaluating a number of alternative model structures as indicated above. All of these tests failed to reject the null hypothesis that IIA holds in this case.

Table 6 summarizes the results from the model estimation for the millennial and nonmillennial segments and the pooled sample; the specific utility functions for the pooled sample (as an example) are presented in the Appendix. A full description of the variables included in the model can be found in Malokin et al. (2019).

Comparing the effects of travel multitasking on mode choice across different population segments is not entirely straightforward. For each segment, the estimated vector of coefficients, $\boldsymbol{\beta}$, is in fact $\mu \boldsymbol{\beta}$, where $\mu$ is an unidentifiable scale parameter that is associated with the assumed extreme value distribution for the error terms of the model, and is inversely related to the variance of that distribution. When only a single sample is involved, the $\mu$ can be fixed at 1 for convenience (Ben-Akiva and Lerman 1985). When estimating separate models for multiple segments, however, it is conceivable that the underlying scale parameters would not be equal for different segments, implying heteroscedasticity (unequal error variances) across the segments. ${ }^{13}$ This could lead to erroneous conclusions if coefficients are compared at their face value. In the following interpretations we refrain from direct comparisons of coefficient magnitudes across segments, but we do point out when a coefficient is significant for one segment but not the other. ${ }^{14}$ In addition, comparison across segments is valid if coefficient ratios are used, because the scale parameters cancel out in the ratio. This is true whether comparing the ratio of two coefficients for one segment to the same ratio for

\footnotetext{
${ }^{12}$ We compare segments by the non-adjusted $\rho^{2}$. The adjusted $\rho^{2}$ for the millennial segment is lower than for the pooled model because insignificant coefficients remained in the specification and the sample size substantially decreased, allowing the lack-of-parsimony penalty to play a greater role.

13 For example, one study of promotion to Associate Professor for biochemists posited "more heterogeneous career patterns" for women than for men as a plausible reason to expect scale differences across gender (Allison, 1999, p. 190).

14 If an insignificant coefficient is taken to equal zero - a practice that is extremely common but controversial (see, e.g., Hauer, 2004) - then comparison of a zero to a non-zero coefficient across segments is legitimate, since accounting for differences in scale would still leave the zero as a zero.
} 
Table 6 Weighted multinomial logit mode choice models for the millennial and non-millennial segments and the pooled sample

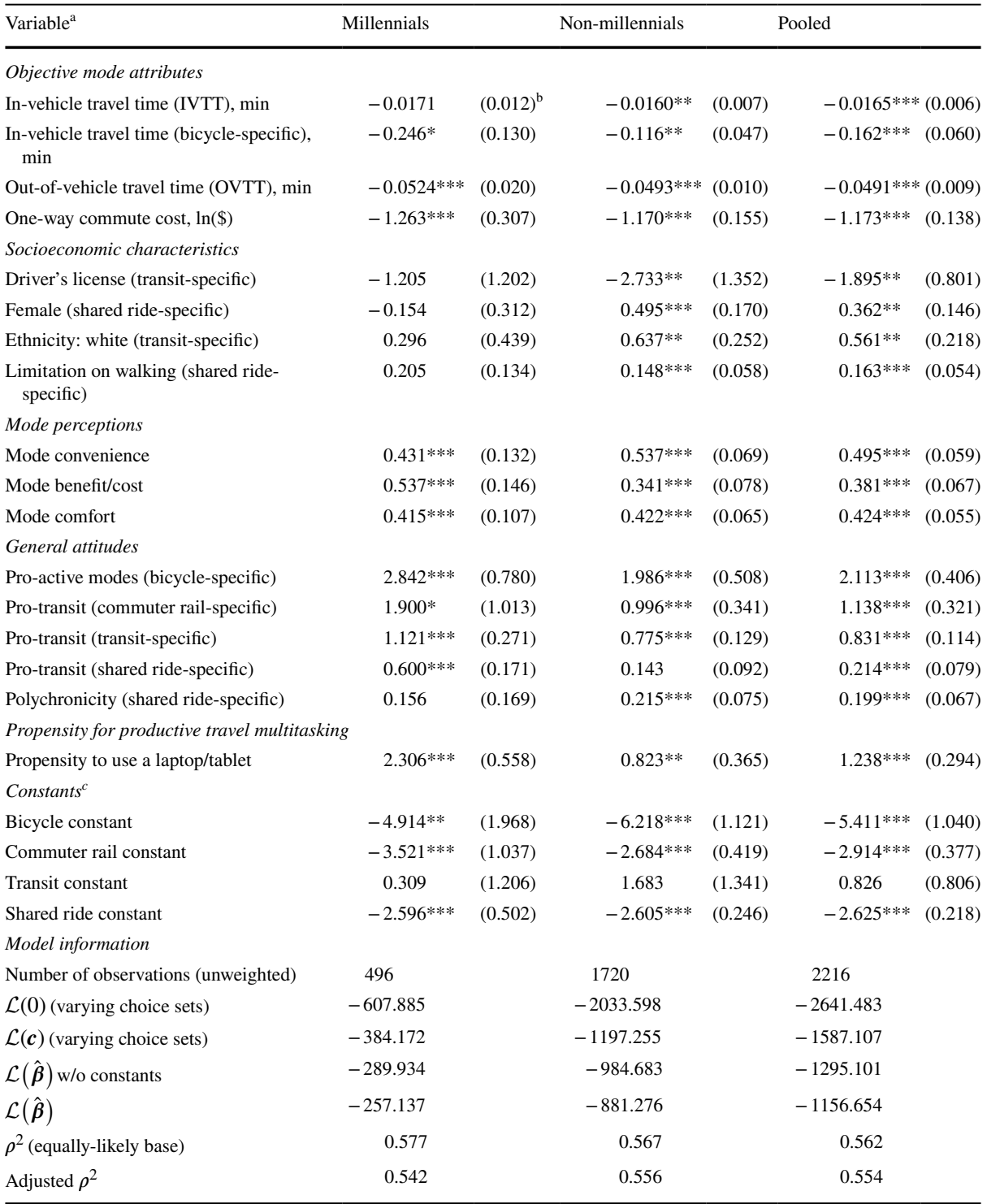

Significance: *** means $p<0.001, * *$ means $p<0.01, *$ means $p<0.05$

${ }^{a}$ Coefficients are equal across any modes not directly named. Specifically, the IVTT coefficient is equal across all modes except bicycle; the OVTT, one-way commute cost, mode perception, and laptop propensity coefficients are equal across all modes; and all other coefficients are specific to the named mode. See the Appendix for the fully-expressed utility functions of the pooled model

${ }^{b}$ Effects of the variables are represented by an estimated coefficient and standard error (in parentheses)

${ }^{\mathrm{c}}$ Driving alone is the base alternative for each model 
the other segment (as in comparing VOTT and WTP across segments), or comparing the ratio across segments of coefficients for one variable to the same ratio for another variable. ${ }^{15}$

While some of the coefficients are not statistically significant in the model for millennials, all coefficients of interest to this study (travel time, travel cost and propensity to use a laptop) are significant, except (interestingly) for in-vehicle travel time (IVTT). The millennials' IVTT coefficient should not be considered unimportant, however. Rather, its insignificance is arguably due to its relatively large standard error, which, in turn, is a function of the relatively smaller size of the millennials sample. As a reviewer pointed out, in revealed preference data, travel times and travel costs are often highly correlated, and the present sample is no exception. From Tables 11, 12, 13 and 14 in the Appendix, note that the correlations of cost with IVTT range from 0.4 to 0.8 for both cohorts (with the high end of that range pertaining to the most-often chosen mode, driving alone), but the larger sample size of the non-millennials cohort allows both time and cost to achieve significance in the models for them and for the pooled sample. Finally, the insignificance of this coefficient may also reflect comparatively greater heterogeneity in the impact of IVTT on utility among millennials, leading to greater uncertainty in the estimate of the single "average" coefficient for the younger group.

Owning a driver's license has a negative coefficient (with respect to the transit alternative) and is significant for non-millennials only, indicating that having a driver's license does not lower the utility of taking transit among millennials. Non-millennial women obtain higher utility than their male counterparts from taking a shared ride. The same variable has a negative but statistically insignificant coefficient for millennials, suggesting that young females derive similar utility from carpooling as do young males. An analogous situation happens with respect to ethnicity: older white adults are more likely than older non-whites to take transit (in the study area the transit network substantially-though of course not exclusively — serves affluent, predominantly white, residential areas), while the insignificant coefficient in the millennial segment suggests that for younger adults, ethnicity does not play a role in choosing between riding transit and the reference alternative of driving alone.

Since mode perceptions and most attitudes are significant for both segments, we compare segments by examining selected coefficient ratios. Comparing the coefficients for mode convenience and benefit/cost, we note that for millennials, benefit/cost is more important than convenience, while for non-millennials the opposite is true. This effect may reflect millennials' search for a mode with the best value (e.g., lower costs, greater benefits) even if it is less convenient.

With respect to the pro-transit attitude coefficients, it is convenient to benchmark them against the generic IVTT coefficient, and since the ratio of generic IVTT coefficients is close to unity between the two segments, it is convenient to compare that ratio to the ratio across segments of the three mode-specific pro-transit attitude coefficients. From Table 6 we can see

15 If superscripts $\mathrm{M}$ and $\mathrm{N}$ represent millennials and non-millennials, respectively, and subscripts 1 and 2 represent variables 1 and 2, respectively, then it is easy to see that ratios of the coefficients for variables 1 and 2 are comparable across segments: $\frac{\mu^{M} \beta_{1}^{M}}{\mu^{M} \beta_{2}^{M}}=\frac{\beta_{1}^{M}}{\beta_{2}^{M}}$ and $\frac{\mu^{N} \beta_{1}^{N}}{\mu^{N} \beta_{2}^{N}}=\frac{\beta_{1}^{N}}{\beta_{2}^{N}}$. However, comparing ratios of the coefficients for variable 1 across segments to the ratio for variable 2 is also legitimate: in comparing $\frac{\mu^{M} \beta_{1}^{M}}{\mu^{N} \beta_{1}^{N}}$ to $\frac{\mu^{M} \beta_{2}^{M}}{\mu^{N} \beta_{2}^{N}}$, the common ratio $\frac{\mu^{M}}{\mu^{N}}$ can be ignored. Or, put another way, in the ratio of ratios, $\frac{\mu^{M} \beta_{1}^{M}}{\mu^{N} \beta_{1}^{N}} / \frac{\mu^{M} \beta_{2}^{M}}{\mu^{N} \beta_{2}^{N}}$, the scale factor ratios cancel, so that one is effectively comparing $\frac{\beta_{1}^{M}}{\beta_{1}^{N}}$ relative to $\frac{\beta_{2}^{M}}{\beta_{2}^{N}}$. To the extent that that ratio of ratios is not equal to one, it signifies that there is a genuine difference in coefficients (either for variable 1 , variable 2 , or both) between the two segments, beyond any difference in scale. 
Table 7 Weighted VOTT and WTP for Productive Multitasking for the Millennial and Non-Millennial Segments and the Pooled Sample

\begin{tabular}{|c|c|c|c|c|c|c|}
\hline Parameter & \multicolumn{2}{|c|}{ Millennials } & \multicolumn{2}{|c|}{ Non-Millennials } & \multicolumn{2}{|c|}{ Pooled } \\
\hline$N$ & \multicolumn{2}{|l|}{496} & \multicolumn{2}{|l|}{1720} & \multicolumn{2}{|l|}{2216} \\
\hline$\rho^{2}$ & \multicolumn{2}{|c|}{0.577} & \multicolumn{2}{|c|}{0.567} & \multicolumn{2}{|c|}{0.562} \\
\hline$\beta_{I V T T}$ & \multicolumn{2}{|c|}{$-0.0171^{\dagger}$} & \multicolumn{2}{|c|}{-0.0160} & \multicolumn{2}{|c|}{-0.0165} \\
\hline$\beta_{O V T T}$ & \multicolumn{2}{|c|}{-0.0524} & \multicolumn{2}{|c|}{-0.0493} & \multicolumn{2}{|c|}{-0.0491} \\
\hline$\beta_{\ln \text { Cost }}$ & \multicolumn{2}{|c|}{-1.263} & \multicolumn{2}{|c|}{-1.170} & \multicolumn{2}{|c|}{-1.173} \\
\hline \multirow[t]{2}{*}{$\beta_{\text {laptop }}$} & \multicolumn{2}{|c|}{2.306} & \multicolumn{2}{|c|}{0.823} & \multicolumn{2}{|c|}{1.238} \\
\hline & Mean & Median & Mean & Median & Mean & Median \\
\hline$W T P(\text { laptop })_{\text {Rail,DA }}^{\$}$ & 0.55 & 0.06 & 0.30 & 0.02 & 0.42 & 0.02 \\
\hline$W T P(\text { laptop })_{\text {Rail,Transit }}^{\$}$ & 0.21 & -0.03 & 0.16 & -0.03 & 0.21 & -0.03 \\
\hline$W T P(\text { laptop })_{\text {Rail }, D A}^{\min }$ & 14.24 & 3.66 & 4.50 & 0.92 & 6.86 & 1.45 \\
\hline$W T P(\text { laptop })_{\text {Rail }, \text { Transit }}^{\text {in }}$ & 3.33 & -2.90 & 0.60 & -1.60 & 1.07 & -2.20 \\
\hline VOTT for IVTT, \$/h & 1.87 & 1.50 & 2.20 & 1.64 & 2.18 & 1.66 \\
\hline VOTT for OVTT, $\$ / \mathrm{h}$ & 5.70 & 4.59 & 6.76 & 5.04 & 6.50 & 4.93 \\
\hline
\end{tabular}

${ }^{\dagger}$ Significant at $<17 \%$ level

that although the nominal coefficients of IVTT are nearly equal across segments $\left(\frac{\mu^{M} \beta_{I V T}^{M}}{\mu^{N} \beta_{V V T T}^{N}}=-0\right.$ $.0171 /-0.0160=1.069$ ), the nominal (positive) coefficients of the pro-transit attitude for millennials are respectively 1.9, 1.4, and 4.2 times larger than for non-millennials for the commuter rail, transit, and shared ride modes. This indicates that if a millennial and an older commuter have the same pro-transit attitude and IVTT values, the joint contribution of these variables to the utilities of those non-drive alone modes is more positive for the millennial (increasing her probability of choosing them) compared to the older commuter.

Finally, the constant terms for bicycle, commuter rail, and shared ride are negative and significant, indicating that unobserved characteristics tend to favor the reference alternative of driving alone over these modes.

\section{Value of travel time and willingness to pay for laptop usage}

Using the results in Table 6, we can compare the value of travel time (VOTT) and willingness to pay (WTP) for laptop/tablet usage, for the members of the two generational groups. VOTT evaluates the tradeoff, or substitution, between the time and cost of a trip, i.e., how much travelers are willing to pay (be paid) to reduce (increase) their commute time, in order to leave their utility constant. We calculate the VOTT for mode $m$ as the ratio of the derivative of that mode's utility with respect to its travel time (IVTT or OVTT) to the derivative with respect to its cost (Koppelman and Bhat 2006):

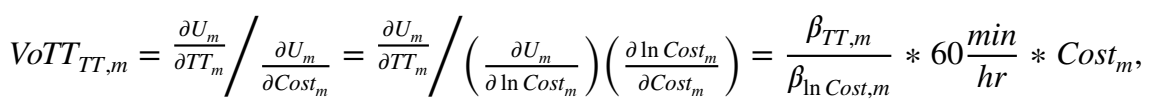

where $V_{T T T_{T T}}$ is the value of travel time for either in-vehicle or out-of-vehicle travel time measured in 2011 US dollars per hour, $\beta_{T T}$ is the estimated coefficient for IVTT or OVTT 
(each measured in minutes), $\beta_{\text {ln Cost }}$ is the estimated coefficient of the natural logarithm of travel cost, and Cost is the individual-specific one-way trip cost expressed in 2011 US dollars. Since travel cost is represented by the natural logarithm of the one-way cost of the commute, the utility function is not linear in cost, and thus VOTT varies by individual: all else equal, the greater a commuter's cost for a trip of a given length, the more she is willing to pay (requires being paid) to save (incur) a fixed amount of time. Table 7 reports the mean and median of the weighted distribution of VOTT for each sample.

We use the WTP for productive multitasking to evaluate the substitution between the propensity to use laptop and either time or cost. In other words, this is a measure of how much (measured in either additional trip time or cost, respectively expressed in minutes and 2011 US dollars) commuters are willing to pay (or be paid) for the ability to use a laptop on the commute. The propensity to use a laptop, which varies between zero and one, is intrinsically composed of two parts: the general conduciveness of the mode to using a laptop and the individual's inclination to engage in this behavior. Thus, it is more realistic to assume a certain cap on the rate of substitution. For example, if allowed to reach the extreme upper value (propensity=1), WTP measures could suggest practically unachievable substitution rates for the target modes (having an absolute conduciveness to use a laptop) or individuals (assuming the maximum inclination for everyone). This is the rationale behind introducing an additional factor into the WTP calculation (Eq. 2). This factor is the difference in the propensity to use a laptop between the reference mode and another, "target", mode. Commuter rail is universally used as the reference mode for conceptual reasons: it presumably provides the best experience for productive multitasking among all modes that are considered. Thus, this formulation of the WTP measures how much travelers are willing to pay in terms of time or money to obtain the same level of productive multitasking on the target mode that they could currently achieve on commuter rail, given their individual tendency for this behavior. For money, the expression is:

$$
W T P_{R, k}^{\text {Cost }}=\frac{\beta_{\text {Laptop }}}{\beta_{\text {ln Cost }}} * \operatorname{Cost}_{k} *\left(\text { Laptop }_{R}-\text { Laptop }_{k}\right),
$$

where $W T P_{R, k}^{\text {Cost }}$ is the willingness to pay in terms of trip cost with the reference mode $R$ and target mode $k, \beta_{\text {Laptop }}$ is the estimated coefficient of the propensity to use a laptop, and Laptop $_{R}$ and Laptop $k$ are the propensities to use a laptop for the reference and target modes respectively. Cost, the laptop variables, and hence the WTP, vary by individual. For time, the equation loses the "cost" factor, and $\beta_{\ln \text { Cost }}$ is replaced by $\beta_{I V T T}$.

We selected two target modes of interest: driving alone and transit. In our formulation, WTP for using a laptop while driving alone implies the adoption of fully autonomous vehicles (AVs), which allows users to experience the same level of multitasking conduciveness that is observed for commuter rail (i.e., an ability to divert attention from the driving task to the cognitively demanding tasks that using a laptop requires). In essence, $W T P_{\text {Rail,DA }}^{x}$ measures the premium (in $x=$ minutes, dollars) that commuters would be willing to pay for productive multitasking while "driving alone" in an AV. Similarly, WTP for productive multitasking while taking transit evaluates the premium that commuters are willing to pay for productive multitasking on public transportation. This could be achievable, to a certain extent, with currently available means, such as providing more room and seating on vehicles, facilitating internet connectivity with accessible Wi-Fi and electric outlets, etc. (though the level of comfort and effects of motion sickness might still make public transportation options less conducive to productive multitasking activities than commuter rail systems). 
In Table 7 we present estimated weighted VOTT and WTP measures for the millennial and non-millennial segments. The discrepancies between the mean and median values for the VOTT and WTP estimates (the mean always being larger), which are more prominent for the latter, arise from highly skewed distributions with heavy right-hand tails. These distributions point to a considerable level of heterogeneity in both segments. Existence of negative WTP values for a sizable number of individuals (which occurs when Laptop $_{R}<$ Laptop $_{k}$ ), indicates that for these individuals, the target mode is already more conducive to productive multitasking (in terms of their specific proclivities) than commuter rail is, and they would need to be paid in order to accept a target-mode conduciveness that is equivalent to that of the inferior (on this dimension, for them) commuter rail value. These results point to the importance of examining variability, not just means, and provide a strong indication that individuals do not always conform to our stereotypical expectations. For more distributional statistics, see Tables 15, 16 and 17 in the Appendix.

Both cohorts, millennials and non-millennials, view their OVTT as more onerous than IVTT, which is consistent with expectations: the OVTT coefficients are more than three times greater in absolute value than the respective IVTT coefficients in each age group. In terms of VOTT, the means and medians for IVTT and OVTT are lower for millennials than for non-millennials. In other words—as conjectured at the outset-millennials, on average, are not willing to pay as much to save each minute of travel as older adults are (15.0 and $15.7 \%$ less for IVTT and OVTT, respectively). When the VOTT computation is broken down into factors, $\operatorname{VoTT}_{I V T T, m}=\frac{-0.0171}{-1.263} * 60 \frac{\mathrm{min}}{\mathrm{hr}} *$ Cost $_{m}=0.81235 *$ Cost $_{m}$ and $\operatorname{VoTT}_{I V T T, m}=\frac{-0.0160}{-1.170} * 60 \frac{\mathrm{min}}{\mathrm{hr}} *$ Cost $_{m}=0.82051 *$ Cost $_{m}$ for millennials and non-millennials respectively, it is apparent that the difference overwhelmingly lies within the distribution of the cost variable between the segments.

We further investigated the chosen mode costs, focusing on the drive-alone mode since it accounts for a $77 \%$ weighted share. The overall drive-alone cost is lower for millennials than for the older generations, and an even deeper investigation of the cost components indicated that millennials tend to have lower commuting costs for each component. Particularly, compared to non-millennials, millennials drive slightly (2\%) more fuel-efficient vehicles, they pay slightly (3\%) lower amounts in tolls, they take slightly (1\%) shorter commutes, and they pay substantially (21\%) less for parking. All these effects compounded cause the average weighted VOTT for millennials to be lower than that for non-millennials.

While the valuation of travel time between segments does not paint an entirely straightforward picture, willingness to pay for using a laptop does. Specifically, millennials consistently have a higher willingness to pay for using a laptop while traveling compared to the non-millennial cohort. On average, they are willing to pay for the ability to use a laptop in a(n autonomous) vehicle $\$ 0.55$ (or $14.2 \mathrm{~min}$ ) per one-way commute, while non-millennials are willing to pay only $\$ 0.30$ (or have a commute that is $4.5 \mathrm{~min}$ longer). Similarly, in the case of public transit, millennials are willing to pay $\$ 0.21$ (or $3.3 \mathrm{~min}$ ) for the same ability, while non-millennials would make the same substitution only for $\$ 0.16$ or $0.6 \mathrm{~min}$ per commute. All these estimates show that millennials are more sensitive to the ability to use a laptop/tablet while commuting, and accordingly present a potential market for multitasking-friendly travel options (e.g., autonomous vehicles, ride-hailing alternatives, public transit improvements, etc.).

A critic might point out that neither of our models controls for income, and therefore wonder whether the difference between the market segments could be simply explained by the fact that millennials are, on average, earning less than their career-advanced counterparts. However, our experimentation showed that including attitudinal variables in the 


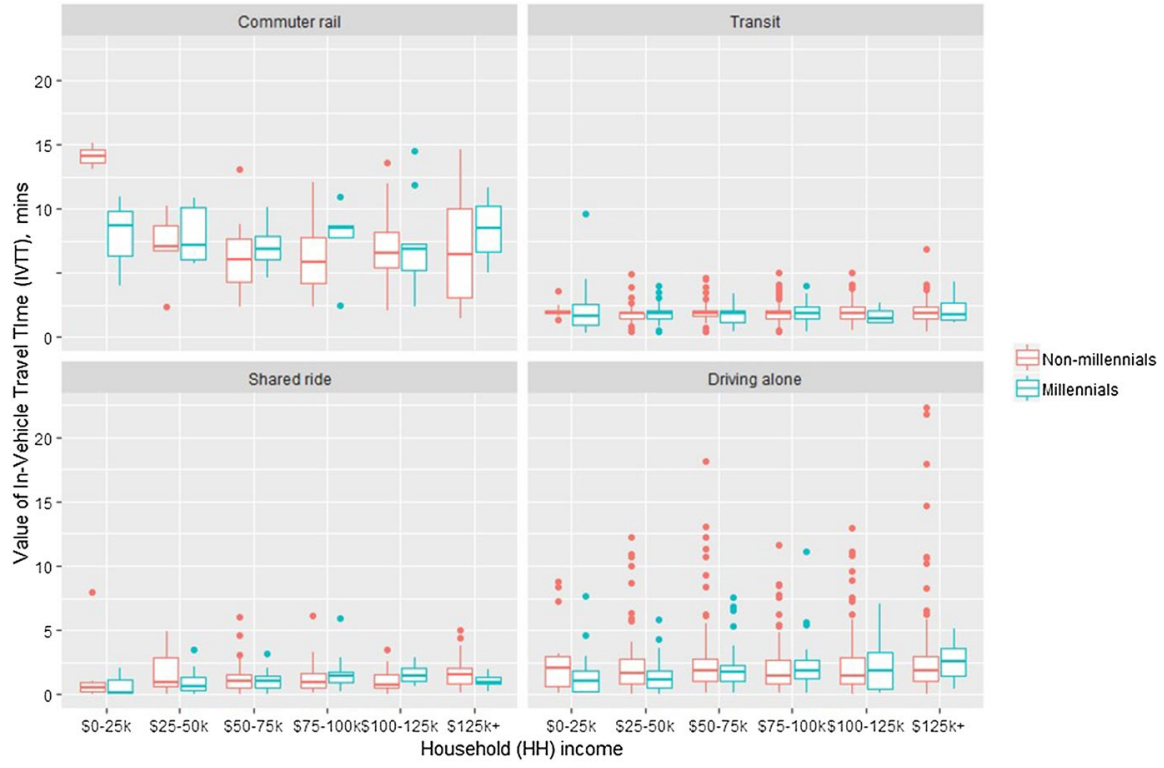

Fig. 1 Cross-tabulation of VOTT of IVTT given commute mode and household income for millennials and non-millennials

model rendered household income indicators insignificant for every segment. ${ }^{16}$ Moreover, stratifying the estimated VOTT and WTP measures by cohort, chosen mode, and household income categories (Fig. 1) exhibits no clear relationship among these variables. As the next section shows, the attitudinal variables themselves make a pronounced contribution to the observed discrepancies between millennials and non-millennials with respect to VOTT and WTP measures.

\section{Sensitivity analysis}

Our estimated VOTT measures (Table 7) are on the lower side of the range found in the literature. On the one hand, if meta-analysis models are applied, the expected VOTT of IVTT would be \$3.78/h and \$4.81/h (Shires and de Jong 2009; Abrantes and Wardman 2011, respectively), correcting for historical currency exchange rates and inflation-values that are not out of scale with ours. On the other hand, our preferred MNL model, which contains attitudinal and multitasking attributes (Table 6), produces even lower VOTT measures (Table 7) than the meta-analysis would suggest. These additional variables, which are absent from most specifications found in the literature and practice, could decrease VOTT estimates by interacting with travel time and travel cost and decreasing their direct effects on utility.

To evaluate the effect on the VOTT estimates of having different combinations of the explanatory variables, we tested several specifications of the MNL model. In Table 8, the first specification contains only mode attributes (travel time and travel cost) and

\footnotetext{
16 When we replicated the results of Table 8 while respectively including household or personal income despite their insignificance, the numerical results changed, of course, but all of the important relationships between IVTT and OVTT, between millennials and non-millennials, and across specifications are still qualitatively true. The relevant VOTT and WTP results are shown in Table 18 of the Appendix.
} 


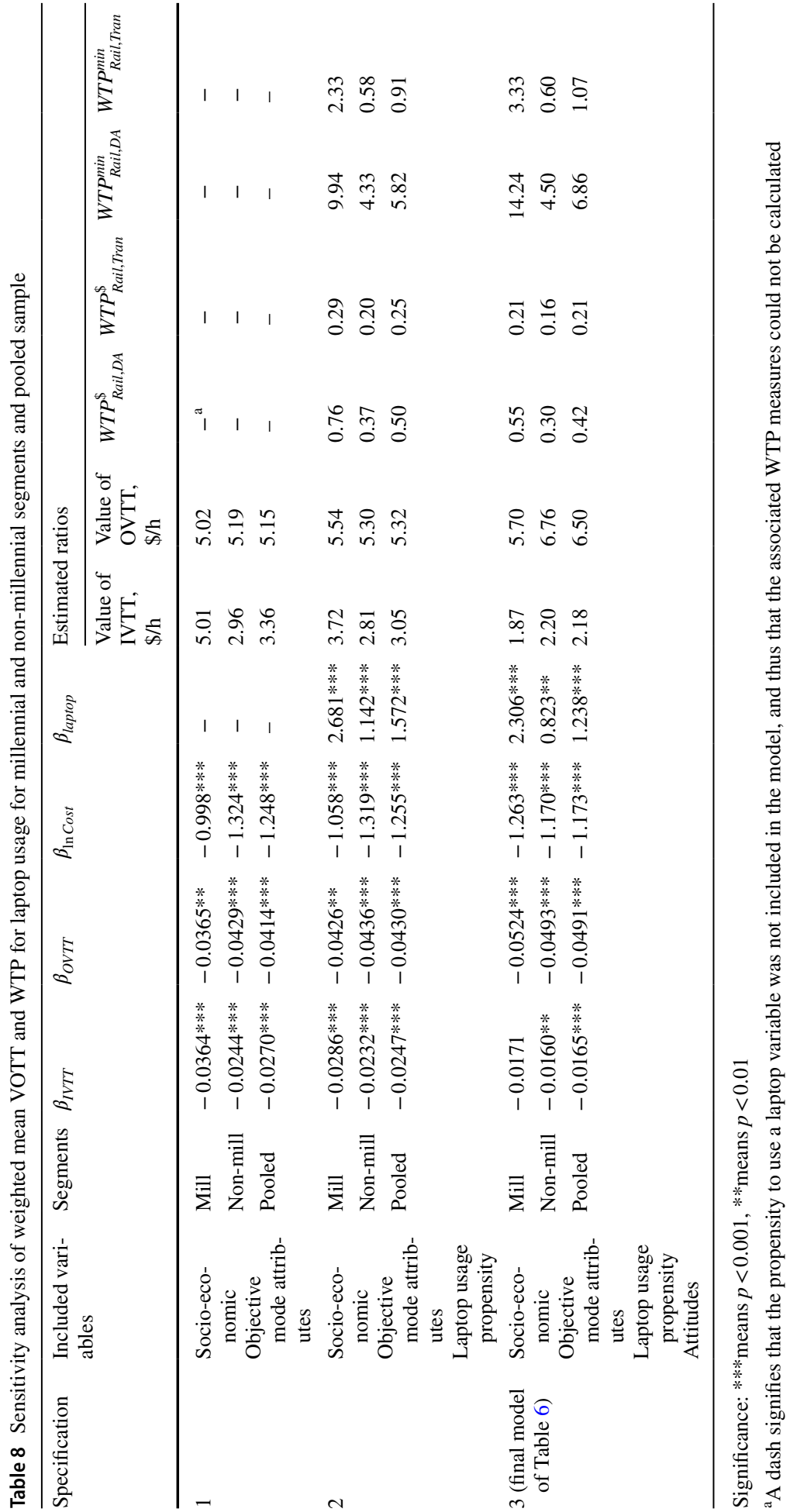


socio-economic characteristics as explanatory variables, representing a conventional formulation of the model. The VOTT of IVTT for the pooled model, $\$ 3.36 / \mathrm{h}$, is very close to the meta-analysis estimates mentioned above. There is a substantial difference between the VOTT of IVTT for the millennial and non-millennial segments, with the former (counterintuitively) being $69 \%$ higher than the latter. Compared to this divergence, VOTT measures associated with OVTT are virtually equal between the segments.

A much greater impact is associated with the inclusion of the propensity to use a laptop along with the mode attributes and socio-economic characteristics in the model (Specification 2). While non-millennials do not demonstrate any large shifts in either VOTT estimate, the VOTT with respect to IVTT for the millennial group decreases by $\$ 1.29 / \mathrm{h}(26 \%)$ and the VOTT for OVTT increases by $\$ 0.52 / \mathrm{h}(10 \%)$.

Finally, for completeness, the third specification includes all explanatory variables from Table 6 and replicates the VOTT and WTP ratios from Table 7. By including attitudinal variables (mode perceptions and general attitudes) in the pool of explanatory variables, the mean VOTT with respect to IVTT for the millennial segment decreases substantially (by $\$ 1.85 / \mathrm{h}$, or $50 \%$ ), with a coincidentally similar increase (by $\$ 1.46 / \mathrm{h}$, or $28 \%$ ) in the mean VOTT with respect to OVTT for the non-millennial segment. In this model alone, the VOTT for IVTT and OVTT are lower for millennials (by 15-16\%) than for non-millennials. It should be emphasized that for both specifications that include the laptop variable (i.e., models 2 and 3 ), the WTP (in either time or money) to use a laptop is substantially higher for millennials. However, for Specification 3, the WTP for using a laptop experienced a decrease in terms of monetary valuation and an increase in temporal valuation, for both segments.

It is tempting to analyze changes in the travel time, cost, and laptop coefficients themselves across the specifications of Table 8, but this would not be appropriate. The reason is that moving variables (attitudes and the laptop propensity) from unobserved (" $\varepsilon$ ") to observed (" $V$ ", in the common notation for discrete alternative utilities) changes $\operatorname{Var}(\varepsilon)$ and hence the scale of the coefficients in the model (Ben-Akiva and Lerman 1985)—possibly differently for each segment. Thus, even within a given segment, when we see a coefficient decrease or increase across specifications, we are seeing the confounding of scale changes and true changes in coefficients as a function of correlations among the included (vs. excluded) explanatory variables. When comparing across segments, we have the added confound that perhaps the scale is changing differently across segments as we change the specification. By confining our attention to changes in VOTT and WTP, we avoid this issue, since the unknown scale parameter cancels out in the ratio of two coefficients.

With that in mind, considering the range of specifications shown in Table 8, we can summarize the trends as follows: failing to separate out the effects of multitasking-related variables overestimates both cohorts' VOTT for IVTT and underestimates it for OVTT. The overestimation of in-vehicle VOTT is substantially greater for millennials (by a factor of more than 2.5, between specifications 1 and 3) than for non-millennials (by 35\%, between the same two models), while the underestimation of out-of-vehicle VOTT is substantially lower for both segments, but somewhat greater (23\%) for non-millennials than for millennials (12\%).

\section{Discussion and conclusions}

The millennial generation is a target population for many ICT technologies that have gained prominence within the last decades. As these new ways to create, transfer, and consume information streams permeate modern lifestyles, it is inevitable to observe some effects on consumed resources (e.g., time, attention) and gained benefits (e.g., productivity, 
happiness) with respect to travel behavior in general and mode choice in particular. Specifically, travel-based ICT use, or multitasking, could be expected to modify the influence on mode utility of objective travel characteristics, especially to diminish the monetized valuation of travel time (VOTT) — an effect which has long been conjectured in the literature.

Using a revealed-preference commute mode choice MNL model estimated on data collected from a purposely-designed survey, we investigated the intersection of these three timely travel behavior topics: the impact of activities while traveling on mode choice, the estimation of WTP and VOTT, and the analysis of the travel behavior of millennials-to our knowledge, the first empirical study to do so. Our comparison of millennial and nonmillennial commuters in Northern California suggests that with respect to influences on their travel behavior, the tastes of younger adults may be shifting, with important implications for planning and modeling purposes.

First, in stark contrast to convention and to the older commuters in our sample (for whom driver's license possession, gender, ethnicity, and walking limitations were significant), we could not find any significant influence of socio-economic variables on the mode choice of younger adults. Given that such variables are significant when attitudes are excluded, this seems to represent another instance in which (particularly for millennials) the available socio-economic variables are serving as proxies for attitudes when those attitudes are unmeasured (for another such example, see Mokhtarian and Salomon 1997). Second, with respect to the impacts of subjective perceptions of commute alternatives on mode choice, benefit/cost is more important than convenience for millennials, while for non-millennials the opposite is true. Third, holding IVTT and support for transit constant, millennials are more likely than non-millennials to choose the commuter rail, transit, and shared ride modes. Fourth, millennials are willing to pay more in time or money than their older counterparts for the ability to use a laptop/tablet while commuting. Finally, VOTT averages for both in-vehicle and out-of-vehicle travel time are lower for millennials than for older adults. Unfortunately, state-of-practice travel behavior models currently lack many of these variables, including the propensity for travel-based multitasking as well as attitudes and other subjective characteristics, which limits the ability of regional planning agencies to accurately represent the impact of changing tastes on mode choice.

The lower VOTT observed for millennials is consistent with expectations, but further investigation found it to be lower for reasons which, at first glance, have nothing to do with travelbased multitasking. Specifically, it is lower because (due to the log transformation of cost in the utility equations) it is a function of cost, and commuting costs tend to be lower for the millennials in our sample. Since this may be partly a function of their junior status in the workforce, the effect is not likely to persist over time. Looking more closely, however, we realize that a differential effect of travel multitasking is manifested in at least two ways - one directly, and one more indirectly. First, as mentioned above, the willingness to pay (either in time or in money) for the ability to use a laptop on the commute is markedly higher for millennials than for older commuters. Second, a sensitivity analysis showed that when multitasking perceptions, preferences, and propensities are not separately accounted for (i.e., when those effects are absorbed into the coefficients of travel time and cost in particular), counterintuitive results emerge. Specifically, in a conventionally-specified model the VOTT for IVTT among millennials is unexpectedly (1) higher than that of non-millennials, and (2) equal to, instead of lower than, that of millennials' VOTT for OVTT. This highlights the value of accounting, and the need to account, for these benefits in an explicit way, as our final model does.

We speculate that the findings of this study portend diverse shifts in future travel demand, potentially including (1) proliferation of urban sprawl due to an increased willingness of travelers to accept longer and costlier commutes; (2) increased market shares of 
modes that are suitable for travel-based multitasking (public transit nowadays, autonomous vehicles in the future); and (3) induced travel demand due to the ever-increasing volume of travel-related information (e.g., the availability of attractive destinations). However, considerable additional study will be needed to evaluate these conjectures.

Several limitations of this study could affect the generalizability of the results. First, the data on which the analysis is based was obtained from a relatively affluent and urbanized slice of the U.S. population (specifically, in Northern California). The available transportation options and their characteristics, lifestyles and employment, access to ICTs, and the usage patterns of the latter will differ across the United States and globally. Second, as information technology advances rapidly, consumer ICT products and services have a very short lifecycle. ${ }^{17}$ Taking this into account, it is reasonable to wonder whether data collected in 2011-2012 produces results that are relevant today. We argue that while the technology changes rapidly, the underlying purposes for which this technology is being used (e.g., productive, recreational, etc.) are much more stable, which allows transferability of the results over time. We also argue that the methodology itself has persistent value, to the present type of application as well as to many others (Malokin et al. 2019).

Third, even though we collected observations about more than 20 activities commuters could perform while traveling, we focus only on one (using a laptop/tablet) to analyze the impact on VOTT of travel-based multitasking. This choice was guided by the multicollinear relationships between the activities (e.g., various types of similar activities performed with the same medium) and by targeting productive travel-based multitasking, as it, arguably, may have the most prominent impact on mode choice and VOTT. Fourth, the millennials' coefficient of the important IVTT variable was statistically insignificant $(p=0.15)$, probably due to the relatively small size of the segment combined with the sizable correlation between travel time and cost. This means that the estimate of that coefficient, albeit non-trivial and plausible, is not as stable as desired; a different sample (even from the same geographic region) could have produced an estimate different enough from the present one to substantially change the results.

Fifth, the model formulation used here presumes that attitudes cause behavior but does not allow for the converse. There has been recently-renewed discussion in the transportation literature regarding which direction of causality is dominant (e.g. Kroesen et al. 2017), and indeed, both directions are conceptually defensible. However, it would have been impossible to estimate a conceptually appropriate structural equation system incorporating both directions of causality, having a multinomial discrete choice model at its heart (see, for example, Maddala 1983, Section 5.7 and the discussion of the problems doing so even with only a binary choice model in Mishra et al. 2019, p. 109). Reviewers suggested using a hybrid choice model formulation, but (1) we do not recall seeing such a formulation used in as complex a model as this one, which includes seven latent variables appearing at 25 different places among the five utility functions; (2) hybrid choice models permit simultaneous estimation of model parameters, but provide no insight into the directionality of causal influence (Chorus and Kroesen 2014); and (3) as typically constructed, hybrid

\footnotetext{
17 While the brand or form factor (a hardware design standard that shares similar size, shape, and other physical specifications, e.g., a desktop tower, flip phone, etc.) of a certain ICT product could be the same across a number of years, the content and the scope of such a product would, most likely, be quite different. For example, compare the heavy and bulky laptops from the early 1990s to the ultra-thin and light laptops of the late $2010 \mathrm{~s}$; or compare the range of functionality of early smartphones from the mid-2000s to the latest consumer offerings today.
} 
choice models do not automatically account for endogeneity (Budziński and Czajkowski 2018). Accordingly, while the formulation used in this study is consistent with what is still mainstream practice and represents our informed judgment regarding dominant (near-term) directions of causality, it does not completely capture all plausible relationships and the resulting estimated parameters may suffer from endogeneity bias.

To address these limitations to the current study, future research would benefit from broadening the scope in several ways. Methodologically similar investigations in the U.S. and around the world could uncover heterogeneity across various populations and geographies. Additionally, these investigations would allow understanding historical trends of activity engagement across multiple generations (i.e., including the latest newcomerGeneration Z). Different segmentations could also be pertinent; for example, a recent study of another section of the same survey analyzed in this paper identified latent classes on the basis of an orientation toward working, particularly on the commute (Choi and Mokhtarian 2020). Other types of activities while traveling, such as recreational, maintenance, or social, could be studied to obtain a more complete picture of the relationships among travel-based multitasking, mode choice, and VOTT. Obtaining a larger sample of millennials, and/or combining revealed preference with stated preference data to reduce the empirical correlation between time and cost, could sharpen the estimated coefficients of these crucial variables. And finally, further experimentation with model specifications could be conducted to more fully account for endogeneity.

\section{Appendix: Utility functions of the MNL model on the pooled sample}

Refer to Table 6 of the main paper for full variable names; the individual-specific subscripts have been omitted for simplicity.

$$
\begin{aligned}
& V_{D A}=-0.0165 \mathrm{IVTT}_{\mathrm{DA}}-0.0491 \mathrm{OVTT}_{\mathrm{DA}}-1.173 \ln \left(\text { Cost }_{\mathrm{DA}}\right)+0.495 \text { Conven }_{\mathrm{DA}}+0.381 \text { Ben-cost }_{\mathrm{DA}} \\
& +0.424 \text { Comfort }_{\mathrm{DA}}+1.238 \text { PropPTMT }_{\mathrm{DA}} \\
& V_{S R}=-0.0165 \mathrm{IVTT}_{\mathrm{SR}}-0.0491 \mathrm{OVTT}_{\mathrm{SR}}-1.173 \ln \left(\mathrm{Cost}_{\mathrm{SR}}\right)+0.362 \mathrm{Fem}+0.163 \text { LimWalk } \\
& +0.495 \text { Conven }_{\mathrm{SR}}+0.381 \text { Ben-cost }_{\mathrm{SR}}+0.424 \text { Comfort }_{\mathrm{SR}}+0.214 \text { Pro-transit } \\
& +0.199 \text { Polychron + 1.238 } \text { PropPTMT }_{\mathrm{SR}}-2.625 \\
& V_{T}=-0.0165 \operatorname{IVTT}_{\mathrm{T}}-0.0491 \mathrm{OVTT}_{\mathrm{T}}-1.173 \ln \left(\text { Cost }_{\mathrm{T}}\right)-1.895 \text { DrivLic }+0.561 \text { White } \\
& +0.495 \text { Conven }_{\mathrm{T}}+0.381 \text { Ben-cost }_{\mathrm{T}}+0.424 \text { Comfort }_{\mathrm{T}}+0.831 \text { Pro-transit } \\
& +1.238 \text { PropPTMT }_{\mathrm{T}}+0.826 \\
& V_{R}=-0.0165 \text { IVTT }_{\mathrm{R}}-0.0491 \text { OVTT }_{\mathrm{R}}-1.173 \ln \left(\text { Cost }_{\mathrm{R}}\right)+0.495 \text { Conven }_{\mathrm{R}} \\
& +0.381 \text { Ben-cost } t_{R}+0.424 \text { Comfort }_{R}+1.138 \text { Pro-transit } \\
& +1.238 \text { PropPTMT }_{\mathrm{R}}-2.914 \\
& V_{B}=-0.162 \operatorname{IVTT}_{\mathrm{B}}-0.0491 \mathrm{OVTT}_{\mathrm{B}}-1.173 \ln \left(\mathrm{Cost}_{\mathrm{B}}\right)+0.495 \text { Conven }_{\mathrm{B}} \\
& +0.381 \text { Ben-cost }_{\mathrm{B}}+0.424 \text { Comfort }_{\mathrm{B}}+2.113 \text { Pro-activeModes } \\
& +1.238 \text { PropPTMT }_{\mathrm{B}}-5.411 \text {, }
\end{aligned}
$$

where $\mathrm{DA}=$ drive alone, $\mathrm{SR}=$ shared ride, $\mathrm{T}=$ transit, $\mathrm{R}=$ commuter rail, $\mathrm{B}=$ bicycle. 
Table 9 Means (standard deviations) of objective travel characteristics by mode and cohort

\begin{tabular}{|c|c|c|c|c|c|}
\hline & Biking & Commuter rail & Transit & Shared ride & Driving alone \\
\hline \multicolumn{6}{|l|}{ Millennials } \\
\hline Weighted $\mathrm{N}^{\mathrm{a}}$ & 97 & 226 & 455 & 523 & 514 \\
\hline \multirow[t]{2}{*}{ Travel cost } & 0.00 & 4.06 & 2.26 & 1.18 & 2.95 \\
\hline & $(0.00)$ & $(2.17)$ & $(1.22)$ & (1.07) & $(2.85)$ \\
\hline \multirow[t]{2}{*}{ Ln(travel cost) } & -4.61 & 1.31 & 0.65 & -0.31 & 0.57 \\
\hline & $(0.00)$ & $(0.38)$ & $(0.63)$ & $(1.13)$ & $(1.15)$ \\
\hline \multirow[t]{2}{*}{ IVTT } & 21.37 & 57.19 & 42.81 & 35.73 & 32.40 \\
\hline & $(16.91)$ & $(29.64)$ & $(32.23)$ & $(21.06)$ & $(22.31)$ \\
\hline \multirow[t]{2}{*}{ OVTT } & 0.00 & 25.04 & 23.26 & 0.00 & 0.00 \\
\hline & $(0.00)$ & $(13.86)$ & (14.98) & $(0.00)$ & $(0.00)$ \\
\hline \multirow[t]{2}{*}{ Total travel time } & 21.37 & 82.23 & 66.07 & 35.73 & 32.40 \\
\hline & $(16.91)$ & $(35.74)$ & $(42.91)$ & $(21.06)$ & $(22.31)$ \\
\hline \multicolumn{6}{|l|}{ Non-millennials } \\
\hline Weighted N & 290 & 590 & 1418 & 1652 & 1679 \\
\hline \multirow[t]{2}{*}{ Travel cost } & 0.00 & 4.50 & 2.32 & 1.31 & 3.30 \\
\hline & $(0.00)$ & $(2.45)$ & (1.19) & $(1.29)$ & $(3.46)$ \\
\hline \multirow[t]{2}{*}{$\operatorname{Ln}($ travel cost $)$} & -4.61 & 1.40 & 0.73 & -0.17 & 0.73 \\
\hline & $(0.00)$ & $(0.43)$ & $(0.50)$ & (1.02) & $(1.03)$ \\
\hline \multirow[t]{2}{*}{ IVTT } & 28.12 & 64.81 & 40.83 & 36.15 & 32.95 \\
\hline & (16.98) & $(34.32)$ & $(26.70)$ & (21.05) & $(22.30)$ \\
\hline \multirow[t]{2}{*}{ OVTT } & 0.00 & 26.58 & 24.21 & 0.00 & 0.00 \\
\hline & $(0.00)$ & $(16.74)$ & (14.27) & $(0.00)$ & $(0.00)$ \\
\hline \multirow[t]{2}{*}{ Total travel time } & 28.12 & 91.39 & 65.03 & 36.15 & 32.95 \\
\hline & (16.98) & $(40.61)$ & (36.03) & (21.05) & $(22.30)$ \\
\hline \multicolumn{6}{|l|}{ Pooled } \\
\hline Weighted N & 387 & 816 & 1872 & 2164 & 2194 \\
\hline \multirow[t]{2}{*}{ Travel cost } & 0.00 & 4.38 & 2.31 & 1.28 & 3.22 \\
\hline & $(0.00)$ & $(2.38)$ & $(1.20)$ & $(1.24)$ & $(3.33)$ \\
\hline \multirow[t]{2}{*}{ Ln(travel cost) } & -4.61 & 1.38 & 0.71 & -0.20 & 0.69 \\
\hline & $(0.00)$ & $(0.42)$ & $(0.54)$ & (1.04) & $(1.06)$ \\
\hline \multirow[t]{2}{*}{ IVTT } & 26.43 & 62.70 & 41.31 & 36.05 & 32.82 \\
\hline & (17.19) & (33.25) & (28.15) & (21.05) & $(22.30)$ \\
\hline \multirow[t]{2}{*}{ OVTT } & 0.00 & 26.15 & 23.98 & 0.00 & 0.00 \\
\hline & $(0.00)$ & (16.00) & (14.45) & $(0.00)$ & $(0.00)$ \\
\hline \multirow[t]{2}{*}{ Total travel time } & 26.43 & 88.85 & 65.28 & 36.05 & 32.82 \\
\hline & (17.19) & $(39.52)$ & $(37.81)$ & (21.05) & $(22.30)$ \\
\hline
\end{tabular}

${ }^{\mathrm{a}}$ Number of cases with this mode in their choice set 
Table 10 F-test (significance) on the difference in objective travel characteristics between weighted millennial and non-millennial segments

\begin{tabular}{llcccc}
\hline & Biking & Commuter rail & Transit & Shared ride & Driving alone \\
\hline Travel cost & N/A & 5.74 & 0.92 & 4.03 & 4.20 \\
& & $\left(0.017^{* *}\right)$ & $(0.339)$ & $\left(0.045^{* *}\right)$ & $\left(0.040^{* *)}\right.$ \\
Ln (travel cost) & N/A & 7.55 & 7.08 & 7.55 & 8.82 \\
& & $\left(0.006^{* * *}\right)$ & $\left(0.008^{* * *}\right)$ & $\left(0.006^{* * *}\right)$ & $\left(0.003^{* * *}\right)$ \\
IVTT & 11.50 & 8.66 & 1.70 & 0.15 & 0.23 \\
& $(0.001)$ & $\left(0.003^{* * *}\right)$ & $(0.193)$ & $(0.696)$ & $(0.630)$ \\
OVTT & N/A & 1.52 & 1.48 & N/A & N/A \\
& & $(0.218)$ & $(0.224)$ & & 0.23 \\
Total travel time & 11.50 & 8.86 & 0.26 & 0.15 & $(0.630)$ \\
& $(0.001)$ & $\left(0.003^{* * *}\right)$ & $(0.613)$ & $(0.696)$ & \\
\hline
\end{tabular}

$* * *, * *$ Significant at $1 \%, 5 \%$

Table 11 Pearson correlations of objective commuter rail characteristics by cohort

\begin{tabular}{|c|c|c|c|c|c|}
\hline & \multicolumn{5}{|c|}{ Millennials $(N=226)$} \\
\hline & Cost & $\operatorname{Ln}($ cost $)$ & IVTT & OVTT & TT \\
\hline \multicolumn{6}{|c|}{ Non-millennials $(N=590)$} \\
\hline Cost & 1 & $.966 * * *$ & $.553 * * *$ & -.042 & $.443 * * *$ \\
\hline $\operatorname{Ln}(\cos t)$ & $.953 * * *$ & 1 & $.565^{* * *} *$ & .000 & $.469 * * *$ \\
\hline IVTT & $.538^{* * *}$ & $.529 * * *$ & 1 & $.252 * * *$ & $.927 * * *$ \\
\hline OVTT & $-.087 * *$ & -.055 & $.167 * * *$ & 1 & $.597 * * *$ \\
\hline Total travel time & $.419 * * *$ & $.424 * * *$ & $.914^{* * * *}$ & $.553 * * *$ & 1 \\
\hline
\end{tabular}

The upper diagonal of the table gives the correlations for millennials, while the lower diagonal gives them for non-millennials. The sample sizes are the weighted number of cases having commuter rail in their choice set

$* * *, * *$ Significant at $1 \%, 5 \%$ 
Table 12 Pearson correlations of objective transit characteristics by cohort

\begin{tabular}{|c|c|c|c|c|c|}
\hline & \multicolumn{5}{|c|}{ Millennials $(N=455)$} \\
\hline & Cost & $\operatorname{Ln}(\cos t)$ & IVTT & OVTT & $\mathrm{TT}$ \\
\hline \multicolumn{6}{|c|}{ Non-millennials $(N=1418)$} \\
\hline Cost & 1 & $.913 * * *$ & $.550 * * *$ & $.373 * * *$ & $.544 * * *$ \\
\hline $\operatorname{Ln}(\cos t)$ & $.884 * * *$ & 1 & $.537 * * *$ & $.415 * * *$ & $.549 * * *$ \\
\hline IVTT & $.416^{* * *}$ & $.413^{* * *}$ & 1 & $.597 * * *$ & $.960 * * *$ \\
\hline OVTT & $.248 * * *$ & $.261 * * *$ & $.502 * * *$ & 1 & $.798 * * *$ \\
\hline Total travel time & $.406^{* * *}$ & $.409 * * *$ & $.940 * * *$ & $.768 * * *$ & 1 \\
\hline
\end{tabular}

The upper diagonal of the table gives the correlations for millennials, while the lower diagonal gives them for non-millennials. The sample sizes are the weighted number of cases having transit in their choice set

*** Significant at $1 \%$

Table 13 Pearson correlations of objective shared ride characteristics by cohort

\begin{tabular}{|c|c|c|c|c|c|}
\hline & \multicolumn{5}{|c|}{ Millennials $(N=513)$} \\
\hline & Cost & $\operatorname{Ln}(\cos t)$ & IVTT & OVTT & TT \\
\hline \multicolumn{6}{|c|}{ Non-millennials $(N=1652)$} \\
\hline Cost & 1 & $.827 * * *$ & $.772 * * *$ & N/A & $.772 * * *$ \\
\hline $\operatorname{Ln}(\cos t)$ & $.808 * * *$ & 1 & $.732 * * *$ & N/A & $.732 * * *$ \\
\hline IVTT & $.814 * * *$ & $.735 * * *$ & 1 & N/A & $1.000 * * *$ \\
\hline OVTT & $\mathrm{N} / \mathrm{A}^{\mathrm{a}}$ & N/A & N/A & N/A & N/A \\
\hline Total travel time & $.814^{* * * *}$ & $.735^{* * *}$ & $1.000 * * *$ & N.A & 1 \\
\hline
\end{tabular}

The upper diagonal of the table gives the correlations for millennials, while the lower diagonal gives them for non-millennials. The sample sizes are the weighted number of cases having shared ride in their choice set

*** Significant at $1 \%$

${ }^{\text {a OVTT }}$ is assumed to be 0 for the shared ride mode, so correlations of that variable with the others cannot be computed

Table 14 Pearson correlations of objective drive alone characteristics by cohort ${ }^{\mathrm{a}}$

\begin{tabular}{|c|c|c|c|c|c|}
\hline & \multicolumn{5}{|c|}{ Millennials $(N=514)$} \\
\hline & Cost & $\operatorname{Ln}(\cos t)$ & IVTT & OVTT & TT \\
\hline \multicolumn{6}{|c|}{ Non-millennials $(N=1679)$} \\
\hline Cost & 1 & $.820 * * *$ & $.764 * * *$ & N/A & $.764 * * *$ \\
\hline $\operatorname{Ln}(\cos t)$ & $.801 * * *$ & 1 & $.748 * * *$ & N/A & $.748 * * *$ \\
\hline IVTT & $.806^{* * *}$ & $.750 * * *$ & 1 & N/A & $1.000 * * *$ \\
\hline OVTT & $\mathrm{N} / \mathrm{A}^{\mathrm{a}}$ & N/A & N/A & N/A & N/A \\
\hline Total travel time & $.806^{* * *}$ & $.750 * * * *$ & $1.000 * * *$ & N.A & 1 \\
\hline
\end{tabular}

*** Significant at $1 \%$

The upper diagonal of the table gives the correlations for millennials, while the lower diagonal gives them for non-millennials. The sample sizes are the weighted number of cases having drive alone in their choice set ${ }^{\text {a OVTT }}$ is assumed to be 0 for the drive alone mode, so correlations of that variable with the others cannot be computed 
Table 15 Distribution of VOTT and WTP to use laptop in millennial segment

\begin{tabular}{lrrrrrr}
\hline & \multicolumn{1}{c}{ Mean } & \multicolumn{1}{l}{ 5th\% } & \multicolumn{1}{c}{ 25th\% } & Median & 75th\% & 95th\% \\
\hline WTP Rail-DA, \$ & 1.0628 & -0.2712 & -0.0029 & 0.0312 & 0.6416 & 6.3360 \\
WTP Rail-Transit, \$ & 0.6973 & -0.9289 & -0.1662 & -0.0005 & 0.2967 & 4.9913 \\
WTP Rail-DA, min & 17.1155 & -11.1260 & -0.3396 & 3.1704 & 23.5844 & 98.6188 \\
WTP Rail-Transit, min & 7.4873 & -28.0932 & -8.0282 & -0.2191 & 10.8901 & 81.9448 \\
Value of IVTT, \$/h & 1.8971 & 0.1171 & 0.3426 & 1.4233 & 2.2559 & 6.9150 \\
Value of OVTT, \$/h & 5.7401 & 0.0249 & 1.0466 & 4.3487 & 6.8928 & 21.1282 \\
\hline
\end{tabular}

Table 16 Distribution of VOTT and WTP to use laptop in non-millennial segment

\begin{tabular}{llllrrr}
\hline & Mean & \multicolumn{1}{l}{ 5th\% } & \multicolumn{1}{c}{ 25th\% } & Median & 75th\% & 95th\% \\
\hline WTP Rail-DA, \$ & 0.4047 & -0.0949 & -0.0049 & 0.0200 & 0.2003 & 2.0419 \\
WTP Rail-Transit, \$ & 0.2566 & -0.3047 & -0.0874 & -0.0155 & 0.0819 & 1.5790 \\
WTP Rail-DA, min & 5.3914 & -3.0566 & -0.2778 & 1.1032 & 7.0226 & 30.5848 \\
WTP Rail-Transit, min & 1.7840 & -7.9845 & -3.5008 & -1.0723 & 3.0008 & 25.6362 \\
Value of IVTT, \$/h & 2.3101 & 0.0593 & 0.9427 & 1.7961 & 2.5052 & 7.5916 \\
Value of OVTT, \$/h & 7.0928 & 0.0253 & 2.8983 & 5.5223 & 7.7025 & 23.3409 \\
\hline
\end{tabular}

Table 17 Distribution of VOTT and WTP to use laptop in the whole sample

\begin{tabular}{llrrrrr}
\hline & Mean & \multicolumn{1}{l}{ 5th\% } & \multicolumn{1}{l}{ 25th\% } & Median & 75th\% & 95th\% \\
\hline WTP Rail-DA, \$ & 0.6087 & -0.1454 & -0.0059 & 0.0282 & 0.3189 & 3.0987 \\
WTP Rail-Transit, \$ & 0.3890 & -0.4732 & -0.1241 & -0.0145 & 0.1394 & 2.5245 \\
WTP Rail-DA, min & 8.2697 & -4.5289 & -0.3728 & 1.7006 & 10.7562 & 47.9364 \\
WTP Rail-Transit, min & 2.9697 & -12.2085 & -4.9533 & -1.2111 & 4.9441 & 38.6440 \\
Value of IVTT, \$/h & 2.2763 & 0.0829 & 0.8058 & 1.7320 & 2.5669 & 7.4849 \\
Value of OVTT, \$/h & 6.7616 & 0.0251 & 2.4005 & 5.1595 & 7.6465 & 22.2966 \\
\hline
\end{tabular}




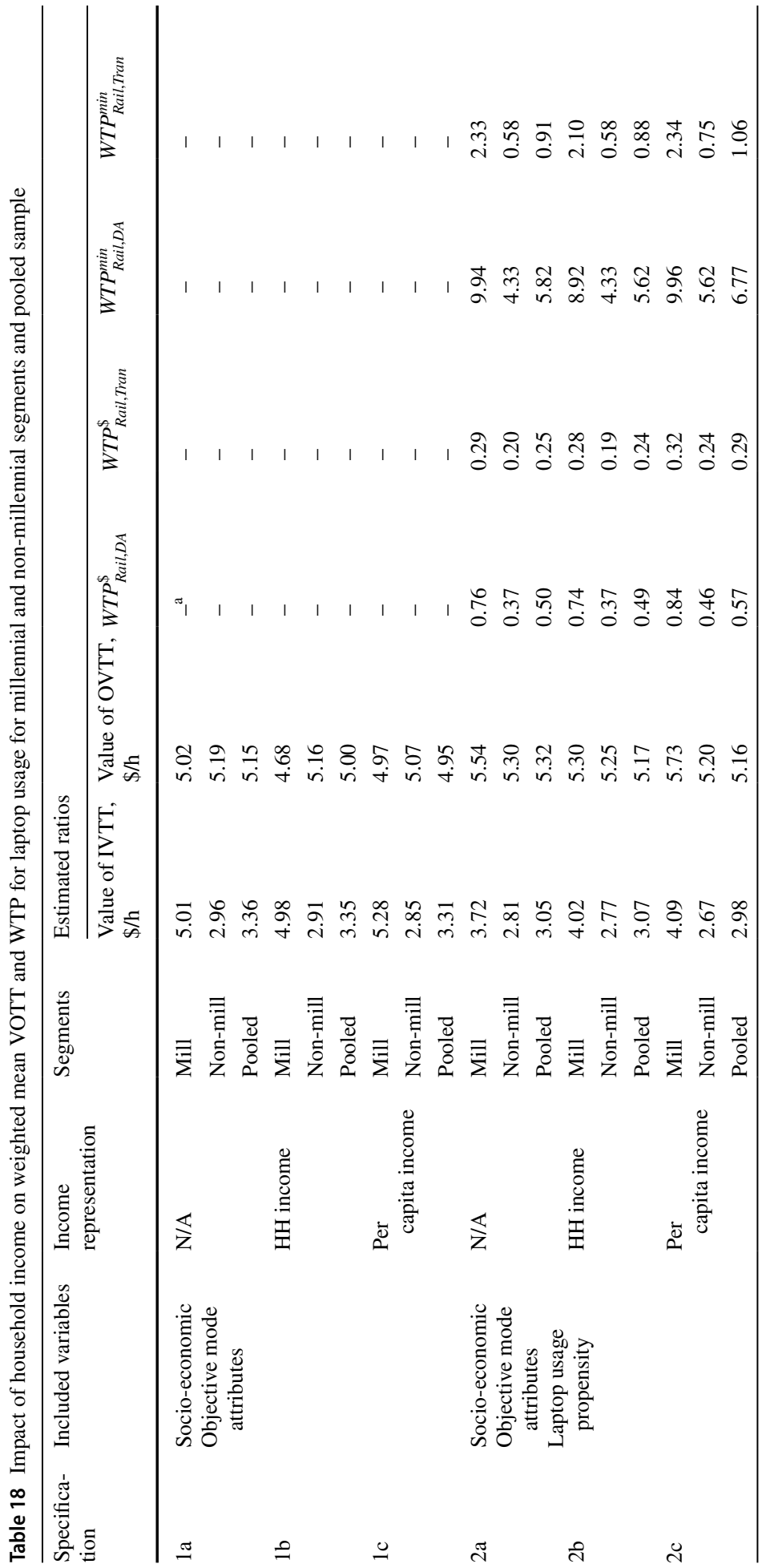




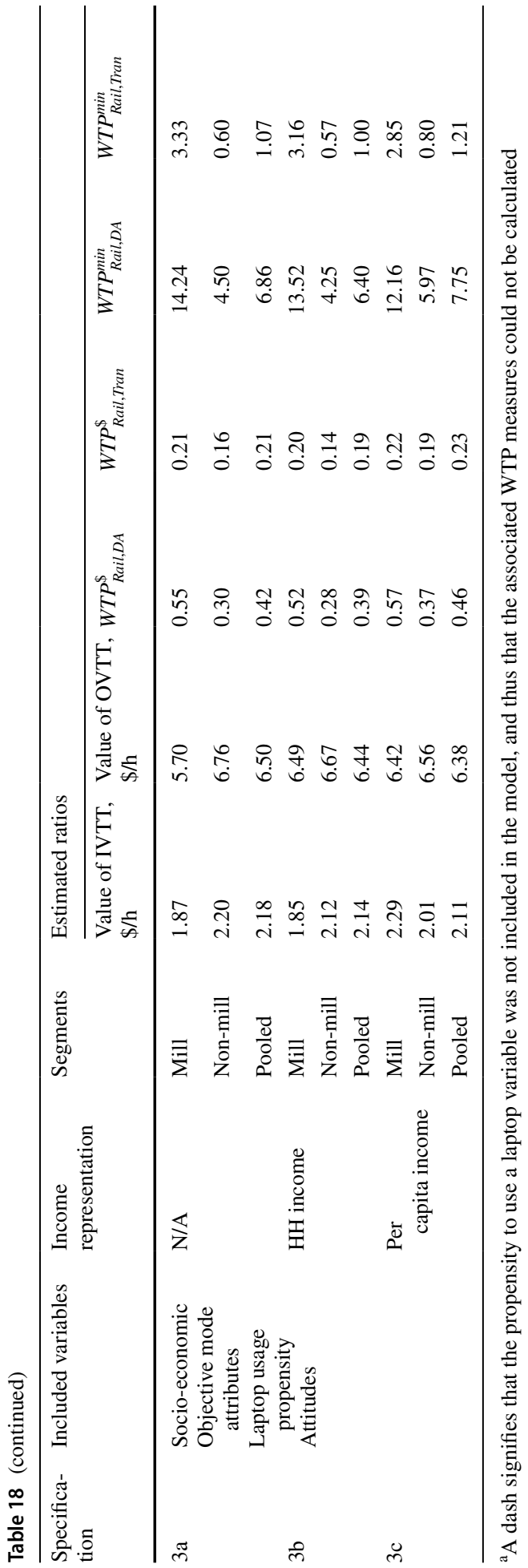


Acknowledgements The funding for this project was provided by the National Center for Sustainable Transportation at UC Davis (which receives funding from the U.S. Department of Transportation and the California Department of Transportation through the University Transportation Centers program); a new faculty grant from the Georgia Institute of Technology; and the Capitol Corridor Joint Powers Authority (CCJPA). We are grateful to Amanda Neufeld and Zhi Dong, who were deeply involved in the survey design, and organized the data collection and cleaning effort. We wish to thank Rosaria M. Berliner and Judith A. Cruz, who contributed to the data modeling, and Javier R. Salgado, who helped with descriptive analysis and additional data cleaning. A deep and heartfelt thanks goes to Sung Hoo Kim, who voluntarily assisted with some final analyses on short notice. We also appreciate the thoughtful comments of three anonymous reviewers, attention to which has substantially improved the paper. An earlier version of this paper was presented at the 96th Annual Meeting of the Transportation Research Board, Washington, DC, January 2017.

\section{Compliance with ethical standards}

Conflict of interest On behalf of all authors, the corresponding author states that there is no conflict of interest.

Open Access This article is licensed under a Creative Commons Attribution 4.0 International License, which permits use, sharing, adaptation, distribution and reproduction in any medium or format, as long as you give appropriate credit to the original author(s) and the source, provide a link to the Creative Commons licence, and indicate if changes were made. The images or other third party material in this article are included in the article's Creative Commons licence, unless indicated otherwise in a credit line to the material. If material is not included in the article's Creative Commons licence and your intended use is not permitted by statutory regulation or exceeds the permitted use, you will need to obtain permission directly from the copyright holder. To view a copy of this licence, visit http://creativecommons.org/licenses/by/4.0/.

\section{References}

Abrantes, P.A.L., Wardman, M.R.: Meta-analysis of UK values of travel time: an update. Transp. Res. A 45, 1-17 (2011)

Allison, P.D.: Comparing logit and probit coefficients across groups. Sociol. Methods Res. 28(2), 186-208 (1999)

Bastian, A., Börjesson, M., Eliasson, J.: Explaining “peak car” with economic variables. Transp. Res. A 88, 236-250 (2016)

Bastian, A., Börjesson, M., Eliasson, J.: Response to Wadud and Baierl: 'Explaining 'peak car' with economic variables: an observation”. Transp. Res. A 95, 386-389 (2017)

Ben-Akiva, M.E., Lerman, S.R.: Discrete Choice Analysis: Theory and Application to Travel Demand. MIT Press, Cambridge (1985)

Berliner, R.M., Malokin, A., Circella, G., Mokhtarian, P.L.: Travel-based multitasking: modeling the propensity to conduct activities while commuting. Presented at the 94th Transportation Research Board Meeting, Washington, DC (2015)

Bluedorn, A.C., Kalliath, T.J., Strube, M.J., Martin, G.D.: Polychronicity and the Inventory of Polychronic Values (IPV). J. Manag. Psychol. 14(3/4), 205-230 (1999)

Blumenberg, E., Taylor, B.D., Smart, M., Ralph, K., Wander, M., Brumbaugh, S.: What's youth got to do with it? Exploring the travel behaviors of teens and young adults. Los Angeles: UCTC-FR-2012-14 (2012). https://escholarship.org/uc/item/9c14p6d5. Accessed 22 Aug 2020

Bouscasse, H., de Lapparent, M.: Perceived comfort and values of travel time savings in the Rhône-Alpes Region. Transp. Res. A 124, 370-387 (2019)

Brownstone, D., Small, K.A.: Valuing time and reliability: assessing the evidence from road pricing demonstrations. Transp. Res. A 39, 279-293 (2005)

Budziński, W., Czajkowski, M.: Hybrid Choice Models vs. endogeneity of indicator variables: a Monte Carlo investigation (2018). https://pdfs.semanticscholar.org/3acd/e41756982f34389ec6fda2339e6495 d22b7f.pdf. Accessed 23 Aug 2020

Choi, S., Mokhtarian, P.L.: How attractive is it to use the internet while commuting? A work-attitude-based segmentation of Northern California commuters. Transp. Res. A 138, 37-50 (2020)

Chorus, C.G., Kroesen, M.: On the (im-)possibility of deriving transport policy implications from hybrid choice models. Transp. Policy 36, 217-222 (2014) 
Circella, G., Mokhtarian, P.L., Poff, L.K.: A conceptual typology of multitasking behavior and polychronicity preferences. Electr. Int. J. Time Use Res. 9(1), 59-107 (2012). https://jtur.iatur.org/home/artic le/76fb57e3-84b8-43c1-966a-67d281b37e59. Accessed 10 Oct 2019

Daly, A., Hess, S.: VTT or VTTS: a note on terminology for value of travel time work. Transportation 47, 1359-1364 (2019)

Delbosc, A., Currie, G.: Causes of youth licensing decline: a synthesis of evidence. Transp. Rev. 33(3), 271-290 (2013)

DeSerpa, A.C.: Microeconomic theory and the valuation of travel time: some clarification. Reg. Urban Econ. 2, 401-410 (1973)

Ettema, D., Verschuren, L.: Multitasking and value of travel time savings. Transp. Res. Rec. J. Transp. Res. Board 2010, 19-25 (2007)

Ettema, D., Friman, M., Gärling, T., Olsson, L.E., Fujii, S.: How in-vehicle activities affect work commuters' satisfaction with public transport. J. Transp. Geogr. 24, 215-222 (2012)

Federal Highway Administration (FHWA): Travel monitoring: traffic volume trends (2020). https://www. fhwa.dot.gov/policyinformation/travel_monitoring/tvt.cfm. Accessed 22 Aug 2020

Frei, C., Mahmassani, H.S., Frei, A.: Making time count: traveler activity engagement on urban transit. Transp. Res. A 76, 58-70 (2015)

Garikapati, V.M., Pendyala, R.M., Morris, E.A., Mokhtarian, P.L., McDonald, N.: Activity patterns, time use and travel of millennials: a generation in transition? Transp. Rev. 36(5), 558-584 (2016)

Gripsrud, M., Hjorthol, R.: Working on the train: from 'dead time' to productive and vital time. Transportation 39, 941-956 (2012)

Gunn, H.: Spatial and temporal transferability of relationships between travel demand, trip cost and travel time. Transp. Res. E 37, 163-189 (2001)

Guttman, J.M.: Implicit assumption and choices among estimates of the value of time. Transp. Res. Rec. 534, 63-68 (1975)

Hauer, E.: The harm done by tests of significance. Accid. Anal. Prev. 36, 495-500 (2004)

Hensher, D.A., Wang, B.: Productivity foregone and leisure time corrections of the value of business travel time savings for land passenger transport in Australia. Road Transp. Res. J. Aust. N. Z. Res. Pract. 25(2), 15-29 (2016)

Hopkins, D., Stephenson, J.: Generation Y Mobilities: Full Report. Centre for Sustainability (CSAFE), University of Otago (2015). https://ourarchive.otago.ac.nz/bitstream/handle/10523/5641/Hopkins\&Steph enson_2015_GenYMobilities_FullReport.pdf?sequence=1. Accessed 22 Aug 2020

Hössinger, R., Aschauer, F., Jara-Diaz, S.R., Jokubauskaite, S., Schmid, B., Peer, S., Axhausen, K.W., Gerike, R.: A joint time-assignment and expenditure-allocation model: value of leisure and value of time assigned to travel for specific population segments. Transportation 47, 1439-1475 (2020)

Kerr, A., Lennon, A., Watson, B.: The call of the road: factors predicting students' car travelling intentions and behavior. Transportation 37(1), 1-13 (2010)

Keseru, I., Macharis, C.: Travel-based multitasking: review of the empirical evidence. Transp. Rev. 38, 162183 (2018)

Koppelman, F.S., Bhat, C.: A Self Instructing Course in Mode Choice Modeling: Multinomial and Nested Logit Models (2006). http://caee.utexas.edu/prof/bhat/COURSES/LM_Draft_060131Final-06063 0.pdf. Accessed 29 Aug 2018

Kouwenhoven, M., de Jong, G.: Value of travel time as a function of comfort. J. Choice Model. 28, 97-107 (2018)

Kroesen, M., Handy, S., Chorus, C.: Do attitudes cause behavior or vice versa? An alternative conceptualization of the attitude-behavior relationship in travel behavior modeling. Transp. Res. A 101, 190-202 (2017)

Kuhnimhof, T., Armoogum, J., Buehler, R., Dargay, J., Denstadli, J., Yamamoto, T.: Men shape a downward trend in car use amongst young adults—evidence from six industrialized countries. Transp. Rev. 32(6), 761-779 (2012)

Lindquist, J.D., Kaufman-Scarborough, C.: The Polychronic-Monochronic Tendency Model: PMTS scale development and validation. Time Soc. 16, 253-285 (2007)

Lyons, G., Urry, J.: Travel time in the information age. Transp. Res. A 39(2-3), 257-276 (2005)

Maddala, G.S.: Limited-Dependent and Qualitative Data in Econometrics. Cambridge University Press, Cambridge (1983)

Malokin, A., Circella, G., Mokhtarian, P.L.: How do activities conducted while commuting influence mode choice? Testing public transportation advantage and autonomous vehicle scenarios. Presented at the 94th Transportation Research Board Meeting, Washington, DC. Available from the authors and on ResearchGate (2015) 
Malokin, A., Circella, G., Mokhtarian, P.L.: How do activities conducted while commuting influence mode choice? Using revealed preference models to inform public transportation advantage and autonomous vehicle scenarios. Transp. Res. A 124, 82-114 (2019)

McDonald, N.C.: Are millennials really the "go-nowhere" generation? J. Am. Plan. Assoc. 81(2), 90-103 (2015)

Mishra, G.S., Mokhtarian, P.L., Clewlow, R.R., Widaman, K.F.: Addressing the joint occurrence of selfselection and simultaneity biases in the estimation of program effects based on cross-sectional observational surveys: case study of travel behavior effects in carsharing. Transportation 46, 95-123 (2019)

Mokhtarian, P.L., Salomon, I.: Modeling the desire to telecommute: the importance of attitudinal factors in behavioral models. Transp. Res. A 31(1), 35-50 (1997)

Mokhtarian, P.L., Papon, F., Goulard, M., Diana, M.: What makes travel pleasant and/or tiring? An investigation based on the French National Travel Survey. Transportation 42, 1103-1128 (2015)

Nathan, B., Adoue, F., Koning, M., L'Hostis, A.: What value do travelers put on connectivity to mobile phone and Internet networks in public transport? Empirical evidence from the Paris region. Transp. Res. A 130, 158-177 (2019)

Neufeld, A.J., Mokhtarian, P.L.: A Survey of Multitasking by Northern California Commuters: Description of the Data Collection Process. Institute of Transportation Studies, University of California, Davis, Research Report UCD-ITS-RR-12-32 (2012). http://www.its.ucdavis.edu/?page_id=10063\&pub_ id=1802. Accessed 20 Aug 2013

Ohmori, N., Harata, N.: How different are activities while commuting by train? A case in Tokyo. Tijdschrift voor Economische en Sociale Geografie 99(5), 547-561 (2008)

Pew Research Center: Millennials in Adulthood: Detached from Institutions, Networked with Friends (2014). Pew Research Center, Washington, D.C. https://www.pewsocialtrends.org/2014/03/07/mille nnials-in-adulthood/. Accessed 19 Sept 2015

Pudāne, B., Rataj, M., Molin, E.J.E., Mouter, N., van Cranenburgh, S., Chorus, C.G.: How will automated vehicles shape users' daily activities? Insights from focus groups with commuters in the Netherlands. Transp. Res. D 71, 222-235 (2019)

Rasouli, S., Timmermans, H.: Judgments of travel experiences, activity envelopes, trip features and multitasking: a panel effects regression model specification. Transp. Res. A 63, 67-75 (2014)

Rhee, K.-A., Kim, J.-K., Lee, B.-J., Kim, S., Lee, Y.-I.: Analysis of effects of activities while traveling on travelers' sentiment. Transp. Res. Rec. 2381, 27-34 (2013)

Rich, J., Vandet, C.A.: Is the value of travel time savings increasing? Analysis throughout a financial crisis. Transp. Res. A 124, 145-168 (2019)

Schmid, B., Jokubauskaite, S., Aschauer, F., Peer, S., Hössinger, R., Gerike, R., Jara-Diaz, S.R., Axhausen, K.W.: A pooled RP/SP mode, route and destination choice model to investigate mode and user-type effects in the value of travel time savings. Transp. Res. A 124, 262-294 (2019)

Shannon, T., Giles-Corti, B., Pikora, T., Bulsara, M., Shilton, T., Bull, F.: Active commuting in a university setting: assessing commuting habits and potential for modal change. Transp. Policy 13(3), 240-253 (2006)

Shaw, F.A., Malokin, A., Mokhtarian, P.L., Circella, G.: It's not all fun and games: an investigation of the reported benefits and disadvantages of conducting activities while commuting. Travel Behav. Soc. 17, $8-25$ (2019)

Shires, J.D., de Jong, G.C.: An international meta-analysis of values of travel time savings. Eval. Program Plan 32, 315-325 (2009)

Singleton, P.A.: How useful is travel-based multitasking? Evidence from commuters in Portland, Oregon. Transp. Res. Rec. 2672, 11-22 (2018)

Sivak, M., Schoettle, B.: Recent changes in the age composition of drivers in 15 countries. Traffic Injury Prev. 13(2), 126-132 (2012)

Stapleton, L., Sorrell, S., Schwanen, T.: Peak car and increasing rebound: a closer look at car travel trends in Great Britain. Transp. Res. D 53, 217-233 (2017)

Susilo, Y.O., Lyons, G., Jain, J., Atkins, S.: Rail passengers' time use and utility assessment. Transp. Res. Rec. 2323, 99-109 (2012)

Talvittie, A.: Comparison of probabilistic modal choice models: estimation methods and system inputs. Highw. Res. Rec. 392, 111-120 (1972)

Tang, J., Zhen, F., Cao, J., Mokhtarian, P.L.: How do passengers use travel time? A case study of ShanghaiNanjing high speed rail. Transportation 45, 451-477 (2018)

Train, K.: Discrete Choice Methods with Simulation. Cambridge University Press, Cambridge (2009)

Tully, C.: Mobilisierung des Mobilen - Trends in der Jugendmobilität. Der Nahverkehr 29(7-8), 12-15 (2011) 
Varghese, V., Jana, A.: Impact of ICT on multitasking during travel and the value of travel time savings: empirical evidences from Mumbai, India. Travel Behav. Soc. 12, 11-22 (2018)

Wadud, Z., Baierl, M.: Explaining "peak car" with economic variables: a comment. Transp. Res. A 95, 381-385 (2017)

Watts, L., Urry, J.: Moving methods, travelling times. Environ. Plan. D 26, 860-874 (2008)

Zamparini, L., Reggiani, A.: Meta-analysis and the value of travel time savings: a transatlantic perspective in passenger transport. Netw. Spat. Econ. 7(4), 377-396 (2007)

Zhang, J., Timmermans, H.: Scobit-based panel analysis of multitasking behavior of public transport users. Transp. Res. Rec. 2157, 46-53 (2010)

Zheng, Z., Washington, S., Hyland, P., Sloan, K., Liu, Y.: Preference heterogeneity in mode choice based on a nationwide survey with a focus on urban rail. Transp. Res. A 91, 178-194 (2016)

Zhou, J.: Sustainable commute in a car-dominant city: factors affecting alternative mode choices among university students. Transp. Res. A 46(7), 1013-1029 (2012)

Publisher's Note Springer Nature remains neutral with regard to jurisdictional claims in published maps and institutional affiliations.

Aliaksandr Malokin is a data engineer at Invesco. He obtained his PhD in Civil Engineering from the Georgia Institute of Technology, where he studied travel behavior, data fusion, and application of machine learning methods in transportation engineering.

Giovanni Circella is a Senior Research Engineer in the School of Civil and Environmental Engineering of the Georgia Institute of Technology, and the Honda Distinguished Scholar for New Mobility Studies and Director of the 3 Revolutions Future Mobility Program at the University of California, Davis. Dr. Circella's research interests include travel behavior and demand modeling, survey methods, shared mobility, autonomous vehicles, sustainable transportation, and policy analysis.

Patricia L. Mokhtarian is the Susan G. and Christopher D. Pappas Professor of Civil and Environmental Engineering at the Georgia Institute of Technology. She has specialized in the application of quantitative methods to the study of travel behavior for more than 40 years, and is a Past Chair of the International Association for Travel Behaviour Research.

\title{
Authors and Affiliations
}

\section{Aliaksandr Malokin ${ }^{1} \cdot$ Giovanni Circella $^{1} \cdot$ Patricia L. Mokhtarian ${ }^{1} \mathbb{D}$}

\author{
Aliaksandr Malokin \\ amalokin@gatech.edu
}

Giovanni Circella

giovanni.circella@ce.gatech.edu

1 School of Civil and Environmental Engineering, Georgia Institute of Technology, 790 Atlantic

Drive, Atlanta, GA 30332, USA 